\title{
Sex-Dependent Reduction in Mechanical Allodynia in the Sural-Sparing Nerve Injury Model in Mice Lacking Merkel Cells
}

\author{
Sang-Min Jeon, ${ }^{1,2,3 *}$ Dennis Chang, ${ }^{1,2,3 *}$ Aleksander Geske, ${ }^{1,2,3}$ David D. Ginty, ${ }^{4}$ and Michael J. Caterina ${ }^{1,2,3}$ \\ ${ }^{1}$ Department of Neurosurgery, Johns Hopkins School of Medicine, Baltimore, Maryland 21205, ${ }^{2}$ Department of Biological Chemistry and Solomon \\ H. Snyder Department of Neuroscience, Johns Hopkins School of Medicine, Baltimore, Maryland 21205, ${ }^{3}$ Johns Hopkins School of Medicine, \\ Neurosurgery Pain Research Institute, Baltimore, Maryland 21205, and ${ }^{4}$ Department of Neurobiology, Howard Hughes Medical Institute, Harvard \\ Medical School, Boston, Massachusetts 02115
}

Innocuous touch sensation is mediated by cutaneous low-threshold mechanoreceptors (LTMRs). A $\beta$ slowly adapting type I (SAI) neurons constitute one LTMR subtype that forms synapse-like complexes with associated Merkel cells in the basal skin epidermis. Under healthy conditions, these complexes transduce indentation and pressure stimuli into A $\beta$ SAI LTMR action potentials that are transmitted to the CNS, thereby contributing to tactile sensation. However, it remains unknown whether this complex plays a role in the mechanical hypersensitivity caused by peripheral nerve injury. In this study, we characterized the distribution of Merkel cells and associated afferent neurons across four diverse domains of mouse hind paw skin, including a recently described patch of plantar hairy skin. We also showed that in the spared nerve injury (SNI) model of neuropathic pain, Merkel cells are lost from the denervated tibial nerve territory but are relatively preserved in nearby hairy skin innervated by the spared sural nerve. Using a genetic Merkel cell KO mouse model, we subsequently examined the importance of intact Merkel cell-A $\beta$ complexes to SNI-associated mechanical hypersensitivity in skin innervated by the spared neurons. We found that, in the absence of Merkel cells, mechanical allodynia was partially reduced in male mice, but not female mice, under sural-sparing SNI conditions. Our results suggest that Merkel cell-A $\beta$ afferent complexes partially contribute to mechanical allodynia produced by peripheral nerve injury, and that they do so in a sex-dependent manner.

Key words: allodynia; mechanoreceptor; Merkel cell; neuropathic; pain

Significance Statement

Merkel discs or Merkel cell-A $\beta$ afferent complexes are mechanosensory end organs in mammalian skin. Yet, it remains unknown whether Merkel cells or their associated sensory neurons play a role in the mechanical hypersensitivity caused by peripheral nerve injury. We found that male mice genetically lacking Merkel cell-A $\beta$ afferent complexes exhibited a reduction in mechanical allodynia after nerve injury. Interestingly, this behavioral phenotype was not observed in mutant female mice. Our study will facilitate understanding of mechanisms underlying neuropathic pain.

Received June 30, 2020; revised Apr. 17, 2021; accepted May 10, 2021.

Author contributions: S.-M.J., D.C., D.D.G., and M.J.C. designed research; S.-M.J., D.C., and A.G. performed research; S.-M.J., D.C., and M.J.C. analyzed data; S.-M.J., D.C., and M.J.C. wrote the first draft of the paper; S.M.J., D.C., A.G., D.D.G., and M.J.C. edited the paper; S.-M.J., D.C., and M.J.C. wrote the paper.

This work was supported by National Institute of Dental and Craniofacial Research R01DE022750 to M.J.C. and D.D.G.; and the Neurosurgery Pain Research Institute at Johns Hopkins School of Medicine. D.D.G. is an Investigator of the Howard Hughes Medical Institute. We thank Ling Bai for helpful suggestions regarding Trk ¿dtomato mice and for discussing unpublished findings; Daniel Bennett, Neil Bolduc, Luke Davis, John Robinson, lan Reucroft, Julie Gokhale, and Gabriella Muwanga for assistance with genotyping and immunostaining experiments; Xiaobu Ye for assistance with statistical analysis; Jeremy Nathans for providing K14 ${ }^{\text {(re }}$ mice; Lintao Qu, Zhiyong Chen, Yun Guan, and members of the M.J.C., Qu, Latremoliere, and Alexandre laboratories for helpful suggestions; and Yun Guan, Lintao Qu, and LaTasha Crawford for critically reading the manuscript.

*S.-M.J. and D.C. contributed equally to this work.

The authors declare no competing financial interests.

Correspondence should be addressed to Michael J. Caterina at caterina@jhmi.edu.

https://doi.org/10.1523/JNEUROSCI.1668-20.2021

Copyright $\odot 2021$ the authors

\section{Introduction}

Under healthy conditions, innocuous tactile sensation and painful mechanosensation in the skin are mediated by two broad populations of somatosensory neurons, low-threshold mechanoreceptors (LTMRs) and nociceptors, respectively. However, following inflammation or nerve injury, spinal somatosensory circuits exhibit functional changes such that input from LTMRs is inappropriately perceived as painful, a phenomenon known as mechanical allodynia. Cutaneous LTMRs fall into subtypes that vary in their conduction, myelination, adaptation, and anatomic properties, and in their associations with end organs, such as Meissner's corpuscles. Among LTMR subtypes, some studies have implicated rapidly adapting LTMRs (RA LTMRs) as contributors to mechanical allodynia (Garrison et al., 2012; Xu et al., 
2015; Dhandapani et al., 2018). However, the full complement of contributory LTMR subtypes has yet to be defined.

Another population of candidate mediators of allodynia are the A $\beta$ slowly adapting Type I (SAI) LTMRs. These heavily myelinated mechanosensory neurons, which fire in a sustained fashion during prolonged indentation of their cutaneous receptive fields, contribute to perceptions of texture, shape, and active touch (Carvell and Simons, 1990). The mechanosensory function of $\mathrm{A} \beta$ SAI LTMRs is strongly shaped by their functional connections with Merkel cells, specialized derivatives of keratin 17 (K17)-positive basal epidermal keratinocytes that reside close to the epidermal basal lamina (Iggo and Muir, 1969; Hartschuh and Weihe, 1980; Fagan and Cahusac, 2001; Halata et al., 2003; Hitchcock et al., 2004; Woodbury and Koerber, 2007). Most anatomic studies of rodent Merkel cell distribution have focused on those located in hairy skin touch domes, vibrissae, and foot pads (Nurse and Diamond, 1984; Nurse et al., 1984a,b; Mills et al., 1989; Li et al., 2011; Feng et al., 2018). However, the mouse hind paw is comprised of multiple distinct structural domains, including dorsolateral hairy skin, plantar foot pads, smooth glabrous skin proximal to the foot pads, and, in some inbred strains such as C57/BL6, a recently described population of hair follicles in the interpad plantar region that is not observed in rats (Walcher et al., 2018). Merkel cell distribution within these distinct domains has yet to be systematically characterized, either under healthy conditions or following adult denervation.

Like LTMRs, Merkel cells intrinsically transduce mechanical stimuli via the Piezo2 channel (Ikeda et al., 2014; Ranade et al., 2014; Woo et al., 2014). Activation of Merkel cells leads to subsequent communication with neighboring A $\beta$ SAI LTMRs through transmitters that have been reported to include serotonin and norepinephrine (Woo et al., 2015; Chang et al., 2016; Hoffman et al., 2018). Previous studies have established a strong basis for the importance of Merkel cells to the normal physiological function and molecular phenotype of $\mathrm{A} \beta$ SAI LTMRs. In skin-nerve preparations, embryonic Merkel cell $\mathrm{KO}$ results in an absence of $\mathrm{A} \beta$ SAI LTMRs or accelerated inactivation of these fibers during sustained skin stimulation, coupled with reduced high-frequency firing (Maricich et al., 2009; Maksimovic et al., 2014). KO or knockdown of Piezo2 in Merkel cells similarly accelerates $\mathrm{A} \beta$ SAI LTMR adaptation to sustained stimuli and reduces static phase firing (Ikeda et al., 2014; Woo et al., 2014), while embryonic $\mathrm{KO}$ of brain-derived neurotrophic factor in Merkel cells alters the regularity of A $\beta$ SAI LTMR firing and changes gene expression in dorsal root ganglion (DRG) neurons (Reed-Geaghan et al., 2016). Merkel cell absence or functional compromise has been shown in some studies to alter behavioral readouts of basal innocuous mechanosensation, vibrational discrimination, and the suppression of itch (Maricich et al., 2012; Maksimovic et al., 2014; Woo et al., 2014; Feng et al., 2018), although basal responses to innocuous punctate stimuli were intact in another recent study (Neubarth et al., 2020). However, whether Merkel cells and/or A $\beta$ SAI LTMRs participate in pathologic pain has been a subject of less focus. In this study, we therefore sought to examine the necessity of intact Merkel Cell-A $\beta$ SAI LTMR function for mechanical allodynia in the setting of peripheral nerve injury.

\section{Materials and Methods}

\section{Mouse strains}

Trk $C^{\text {tdtomato }}$ and Npy $2 r^{\text {tdtomato }}$ mice have been previously described (Li et al., 2011; Bai et al., 2015). K14 ${ }^{\text {Cre }}$ (Dassule et al., 2000) mice were kindly provided by Jeremy Nathans (Johns Hopkins). Atoh1 $1^{f l / f l}$ (\#008681), Ai9
(\#007909), and C57BL/6J (\#000664) mice were obtained from The Jackson Laboratory. Most transgenic lines were maintained on a genetic background consisting predominantly of $\mathrm{C} 57 \mathrm{BL} / 6$, but with contributions from other strains. Both male and female mice were used for behavioral experiments and were analyzed separately. Mice were at least 7 8 weeks old when the first behavioral testing was performed, which was then followed by spared nerve injury before subsequent testing over a 1 month time course. Both male and female mice were used for immunohistochemistry experiments. These mice were also at least 7-8 weeks old when spared nerve injury was performed. Age-matched littermates of the same sex were assigned to experimental groups based on genotype in KO versus WT comparisons. Age-matched littermates of the same sex were randomly assigned to experimental groups in injured versus sham comparisons. Mice used for parallel comparison between naive and nerve-injured states were all $>7$ weeks old, but were only strictly age-matched for the $56 \mathrm{~d}$ postinjury experiment. Mice were housed with 1-5 animals per cage. Mice were handled and housed in accordance with the Johns Hopkins University Institutional Animal Care and Use Committee guidelines as well as National Institutes of Health's Guide for the care and use of laboratory animals.

\section{Injury model}

Spared nerve injury (SNI) was performed as previously described (Bourquin et al., 2006). In brief, under deep isoflurane anesthesia, the sciatic nerve of mice 7-8 weeks old was exposed in the thigh region, and the tibial and common peroneal nerves were ligated. A small section immediately distal to the ligation was excised. The sural nerve was left intact by avoiding contact with or stretching the nerve. Finally, muscle and skin were sutured in two distinct layers with silk 6-0 and 4-0 sutures, respectively. The tibial nerve sparing variant of SNI (SNIt) was performed the same as above, except that the tibial nerve instead of the sural nerve was spared.

\section{Behavioral testing}

Both male and female mice were used for experiments and were analyzed separately. Mice were at least 7-8 weeks old when the first behavioral testing was performed. Experiments were performed at baseline (usually the day before surgery) and at $3,7,14,21$, and $28 \mathrm{~d}$ after SNI surgery or 3,7 , and $14 \mathrm{~d}$ after SNIt surgery. Behavioral assays were conducted with the experimenter blinded to genotype. Animal numbers for each experiment are indicated in the figures.

Punctate mechanical allodynia. The von Frey assay was used to assess punctate mechanical allodynia. Mice were placed under ventilated Plexiglas boxes on a wire mesh platform and habituated for at least $2 \mathrm{~h}$ per day for at least $2 \mathrm{~d}$ before the experiment. On the test day, mice were habituated for at least $30 \mathrm{~min}$ before the assay. A series of von Frey filaments (North Coast Medical, NC12775-02 to NC12775-09) were applied perpendicularly to the glabrous sural (i.e., lateral, for SNI model) or hairy tibial (i.e., between the foot pads, for SNIt model) area of the plantar surface of the hind paw to the point of bending. The nominal bending forces of the filaments, provided by the manufacturer $(0.02,0.04$, $0.07,0.16,0.4,0.6,1$, and $1.4 \mathrm{~g}$ ) are shown in the figures. Empirical filament forces measured at manuscript submission, were as follows: 0.014 , $0.032,0.064,0.15,0.37,0.54,0.98$, and $1.25 \mathrm{~g}$. Paw withdrawal or flinching immediately on filament application was defined as a positive response. In most cases, for each given force, the filament was applied 5 times to the contralateral (with respect to the injured) hind paw, then applied 5 times to the ipsilateral hind paw. In some cases, ipsilateral and contralateral paws were tested on successive days. Intervals between each application were at least a few seconds to avoid sensitization. The number of positive responses of 5 total applications was calculated as a given animal's response percentage, and this number was used for analysis.

Dynamic mechanical allodynia. A brush assay (Cheng et al., 2017) was used to assess dynamic mechanical allodynia. It was generally performed at least $30 \mathrm{~min}$ after the von Frey assay was completed, on the same platform. A paint brush (Winsor \& Newton Cotman 111 round 0) was stroked very gently and slowly along either the sural nerve-innervated plantar or sural nerve-innervated hairy skin (SNI), or the tibial nerve-innervated plantar skin (SNIt) of the hind paw in the distal to 
proximal direction. The stimulus was applied at an angle to avoid punctate stimulation. Each response was assigned a score ranging from 0 to 3 as follows: 0 , no response; 1 , brief paw withdrawal; 2 , sustained paw withdrawal; 3, sustained paw withdrawal with continued licking and flinching. Only the ipsilateral hind paw was tested. Interstimulus interval was $10 \mathrm{~min}$. A total of four stimuli were applied, and the average score was used for analysis.

Thermal hyperalgesia. The Hargreaves assay was used to assess thermal hyperalgesia. Mice were placed under Plexiglas boxes on a glass platform and habituated for at least $2 \mathrm{~h}$ per day for at least $2 \mathrm{~d}$ before the actual experiment. On the test day, mice were habituated for at least $30 \mathrm{~min}$ before the assay. A radiant heat stimulus was focused on the sural (SNI) or tibial (SNIt) area of the plantar surface of the hind paw, and the withdrawal latency was recorded. The intensity of the heat source (IITC Life Science, model 336) was adjusted such that the baseline latency before injury was $\sim 10 \mathrm{~s}$ across the population. The cutoff time was set at $15 \mathrm{~s}$ to prevent tissue damage. Interstimulus interval was $10 \mathrm{~min}$. Heat stimuli were applied to each hind paw 3 times, and the average for each paw was used for analysis.

\section{Immunohistochemistry}

Male and female mice were anesthetized with intraperitoneal injection of $20 \%$ urethane and perfused with $\sim 5 \mathrm{ml}$ phosphate-buffered saline (PBS), then with $50 \mathrm{ml}$ cold $4 \%$ paraformaldehyde in PBS. L3-L5 spinal cord and L3-L5 DRGs were harvested. Hind paw skin was depilated (Nair hair remover) and harvested. For transverse tissue section preparation, tissues were postfixed in $4 \% \mathrm{PFA}$ at $4^{\circ} \mathrm{C}$ overnight. Tissues were cryoprotected in $30 \%$ sucrose in $\mathrm{PB}$ at $4^{\circ} \mathrm{C}$ overnight, embedded in optimal cutting temperature medium (Tissue-Tek), and stored at $-80^{\circ} \mathrm{C}$. Tissues were cryostat sectioned at $10 \mu \mathrm{m}$ for DRGs, $16 \mu \mathrm{m}$ for hind paw skin, and $30 \mu \mathrm{m}$ for spinal cord. DRGs and skin sections were thawmounted onto glass slides, stored at $-80^{\circ} \mathrm{C}$, and incubated at $30^{\circ} \mathrm{C}-37^{\circ} \mathrm{C}$ for $20 \mathrm{~min}$ immediately before staining. Spinal cord sections were stored at $4^{\circ} \mathrm{C}$ until staining. Slides and tissue sections were washed with $0.1 \%$ Triton X-100 in PBS (PBST.1) $3 \times 10 \mathrm{~min}$. Slides or floating sections were then blocked with $0.3 \%$ Triton X-100 in PBS containing $10 \%$ normal donkey serum or normal goat serum for $1 \mathrm{~h}$ at room temperature. Tissues were incubated overnight with primary antibodies rat anti-K8 (University of Iowa/DSHB, 1:100, \#Troma-1), rabbit anti-K17 (from Pierre Coulombe University of Michigan, 1:1000), chicken anti-NF200 (Aves Labs, 1:200, \#NFH), goat anti-mCherry (Sicgen, 1:500, \#AB0040500), rabbit anti-CGRP (ImmnuoStar, 1:1000, \#24112), rabbit anti-S100 (Dako, 1:200, \#Z0311), Biotin-IB4 (Sigma Millipore, 1:100, \#L2140), and chicken anti-NeuN (Aves Labs, 1:200, \#NUN), at room temperature in a humidity chamber. The following day, tissues were washed with PBST.1 $3 \times 10 \mathrm{~min}$ and then incubated for $1-2 \mathrm{~h}$ at room temperature in a humidity chamber with secondary antibodies; donkey anti-goat Cy3 (Jackson ImmunoResearch Laboratories, 1:500, \#705-166-147), goat anti-chicken 546 (Thermo Fisher Scientific, \#A11040), donkey anti-rabbit 647 (Jackson ImmunoResearch Laboratories, \#711-605-152), goat anti-rat 488 (Jackson ImmunoResearch Laboratories, \#112-545-003), donkey anti-chicken 488 (Jackson ImmunoResearch Laboratories, \#703-545-155), donkey anti-rat 488 (Jackson ImmunoResearch Laboratories, \#712-545-153), goat antichicken 488 (Thermo Fisher Scientific, \#A11039), goat anti-rat Cy3 (Jackson ImmunoResearch Laboratories, \#112-165-167), donkey antichicken Cy3 (Jackson ImmunoResearch Laboratories, \#703-165-155), donkey anti-goat (R\&D Systems, \#NL001), donkey anti-guinea pig 488 (Thermo Fisher Scientific, \#21831), and streptavidin-Dylight 405 (Thermo Fisher Scientific, \#21831). Tissues were then washed with PBS $3 \times 10 \mathrm{~min}$. Floating spinal cord sections were rinsed in water or $0.1 \mathrm{M} \mathrm{PB}$, mounted on slides, and allowed to air dry. Sections were coverslipped using fluoromount-G (Electron Microscopy Sciences, \#17984-25) or Dako fluorescence mounting medium (Dako, \#S3023).

For whole-mount hind paw skin staining, fat and connective tissue were thoroughly removed to facilitate antibody penetration. Tissues were postfixed in $4 \%$ PFA at $4^{\circ} \mathrm{C}$ overnight and then briefly washed with PBS to remove excess PFA. Tissues were washed with $1 \%$ Triton X-100 in PBS (PBST.hi) $10 \times 30 \mathrm{~min}$ for a total of $5 \mathrm{~h}$. Tissues were then incubated with primary antibodies diluted in blocking solution (75\% PBST. hi, 20\% DMSO, 5\% normal donkey/goat serum) for $3 \mathrm{~d}$ at room temperature. Tissues were washed with PBST.hi $10 \times 30 \mathrm{~min}$ and then incubated with secondary antibodies diluted in blocking solution for $2 \mathrm{~d}$ at room temperature. Tissues were then again washed with PBST.hi 10 $\times 30 \mathrm{~min}$ and dehydrated in serial dilutions of $\mathrm{MeOH}(50 \%, 80 \%, 100 \%$ $\mathrm{MeOH}$ for $5 \mathrm{~min}$ each, and an additional $100 \% \mathrm{MeOH}$ for $20 \mathrm{~min}$ ). Finally, tissues were cleared in BABB ( 1 volume benzyl alcohol to 2 volumes benzyl benzoate) for $30 \mathrm{~min}$ and mounted onto slides with $\mathrm{BABB}$. All incubations were done on a rotating or rocking platform.

\section{Image analysis}

Images were acquired using a confocal microscope (Nikon A1) and analyzed blinded to genotype using NIS elements (Nikon) or ImageJ (National Institutes of Health). For hind paw skin whole-mount staining, $z$-stack images $(\sim 100-150 \mu \mathrm{m}$ in total depth) were acquired across the thickness of the skin tissue. The number of Merkel cells, number of hair follicles, number of hair follicles associated with Merkel cells, number of Merkel cell clusters with closely associated nerve terminals, or number of morphologically distinguishable nerve terminal structures was counted from maximal intensity projections of the $z$ stack, sometimes augmented by scrolling through the $z$ stacks, within the skin region targeted in a given experiment. Total branch lengths of individual nerve terminal complexes were measured from maximal intensity projections of $z$ stacks. Values for all parameters were expressed either as numbers within a given skin territory, numbers per unit skin area, percent of a given structure with the indicated characteristics, or total branch length per terminal complex, with each symbol shown in figures derived from an individual mouse. For DRGs, neuronal cell type-specific markers were counted either with or without a pan-neuronal marker $(\mathrm{NeuN})$ as a control for total number of neurons; $\sim 600$ neurons per mouse, derived from multiple sections were counted for each data point.

\section{Experimental design and statistical analysis}

For immunostaining, when comparing only two groups, two-tailed Student's $t$ test was used for analysis. When comparing only the ipsilateral hind paw across multiple time points, one-way ANOVA was used. When comparing ipsilateral versus contralateral hind paw across multiple time points, two-way ANOVA was used. For von Frey behavioral measurements, repeated-measures two-way ANOVA was used to analyze the effects of genotype and/or force at a given time point, or to analyze the effects of genotype and/or time at a given force. For brush and Hargreaves assays, repeated-measures two-way ANOVA was used to analyze the effects of genotype and/or time. ANOVA tests were followed by post hoc Bonferroni multiple comparisons correction for either multiple times or multiple forces, but not both, in a given comparison. In repeated-measures ANOVAs, potential differences related to sphericity were corrected for using the Geisser and Greenhouse method. All data were presented as mean \pm SEM, and the criterion for statistical significance was $p$ value $<0.05$. The exact statistical test used for each experiment and its details can be found in the figure legends and Table 1. Unless otherwise noted, the " $n$ " used for analysis was the number of mice. In the case of ANOVA analyses, $p$ values for the overall comparisons between genotypes are listed on the graphs, and $p$ values at individual forces or time points derived from the Bonferroni corrections are indicated by asterisks, as defined in the figure legends. All analyses were performed using GraphPad Prism 8.

\section{Results}

\section{Merkel cell distribution in the mouse hind paw}

Most anatomic characterization of rodent Merkel cells has been focused on hairy skin and foot pads. However, mouse hind paw skin consists of at least four distinguishable domains (Fig. 1A). To visualize the anatomic distribution of Merkel cells across these domains, we performed whole-mount immunostaining of adult male C57BL/6J mouse plantar hind paw skin (excluding the digits) and neighboring hairy skin, with anti-keratin 8 (K8, Troma-1), followed by tissue clearing (Fig. 1A). Skin was costained 
Table 1. Statistical analysis and the number of animals/samples used in the experiments

\begin{tabular}{|c|c|c|c|}
\hline Figure & Pre hoc & Post hoc & $N$ (number of samples/animals per group) \\
\hline $2 F$ & $\begin{array}{l}\text { (1) One-way ANOVA: } \\
F_{(3,14)}=11.99, p=0.0004^{* * *} \\
\text { (2) Two-way ANOVA: } \\
\text { Time } \times \text { Contra/lpsi: } F_{(2,10)}=2.061, p=0.1781 \\
\text { Time: } F_{(2,10)}=9.103, p=0.0056^{* *} \\
\text { Contra/lpsi: } F_{(1,10)}=37.02, p=0.0001^{* * *}\end{array}$ & $\begin{array}{l}\text { Bonferroni multiple comparisons test: } \\
\text { Baseline vs } 7 \mathrm{~d}: p=0.2581 \\
\text { Baseline vs } 28 \mathrm{~d}: p=0.0007^{* * *} \\
\text { Baseline vs } 56 \mathrm{~d}: p=0.0008^{* * *} \\
\text { Bonferroni multiple comparisons test: } \\
7 \mathrm{~d} \text {, Contra vs Ipsi: } p=0.1509 \\
28 \mathrm{~d} \text {, Contra vs Ipsi: } p=0.0017^{* *} \\
56 \mathrm{~d} \text {, Contra vs Ipsi: } p=0.0188^{*}\end{array}$ & $\begin{array}{l}\text { Baseline: } 5 \\
7 \mathrm{~d}: 5 \\
28 \mathrm{~d}: 5 \\
56 \mathrm{~d}: 3\end{array}$ \\
\hline $2 L$ & $\begin{array}{l}\text { (1) One-way ANOVA: } \\
F_{(3,11)}=11.32, p=0.0011^{* *} \\
\text { (2) Two-way ANOVA: } \\
\text { Time } \times \text { Contra/psi: } F_{(2,8)}=2.696, p=0.1273 \\
\text { Time: } F_{(2,8)}=19.27, p=0.0009^{* * *} \\
\text { Contra/lpsi: } F_{(1,8)}=0.5483, p=0.4802\end{array}$ & $\begin{array}{l}\text { Bonferroni multiple comparisons test: } \\
\text { Baseline vs } 7 \mathrm{~d}: p=0.7900 \\
\text { Baseline vs } 28 \mathrm{~d}: p=0.3887 \\
\text { Baseline vs } 56 \mathrm{~d}: p=0.0045^{* *}\end{array}$ & $\begin{array}{l}\text { Baseline: } 4 \\
7 \mathrm{~d}: 4 \\
28 \mathrm{~d}: 3 \\
56 \mathrm{~d}: 4\end{array}$ \\
\hline $2 M$ & $\begin{array}{l}\text { (1) One-way ANOVA: } \\
F_{(3,11)}=1.245, p=0.3403 \\
\text { (2) Two-way ANOVA: } \\
\text { Time } \times \text { Contra } / \text { psi: } F_{(2,8)}=1.339, p=0.3150\end{array}$ & & $\begin{array}{l}\text { Baseline: } 4 \\
7 \mathrm{~d}: 4 \\
28 \mathrm{~d}: 3 \\
56 \mathrm{~d}: 4\end{array}$ \\
\hline
\end{tabular}

Time: $F_{(2,8)}=0.1046, p=0.9019$

Contra/psi: $F_{(1,8)}=0.5796, p=0.4683$

Two-way ANOVA:

Sex $\times$ Contra/psi: $F_{(1,8)}=1.076, p=0.3299$

Sex: $F_{(1,8)}=3.669, p=0.0918$

Contra//psi: $F_{(1,8)}=62.42, p<0.0001^{* * * *}$

Two-way ANOVA:

Sex $\times$ Contra/lpsi: $F_{(1,8)}=0.5934, p=0.4632$

Sex: $F_{(1,8)}=0.4058, p=0.5419$

Contra/lpsi: $F_{(1,8)}=8.679, p=0.0185^{*}$

Two-way ANOVA:

Sex $\times$ Contra/lpsi: $F_{(1,8)}=0.5263, p=0.4888$

Sex: $F_{(1,8)}=1.269, p=0.2926$

Contra/psi: $F_{(1,8)}=0.6922, p=0.4296$

Two-way ANOVA:

Sex $\times$ Injury: $F_{(1,16)}=3.458, p=0.0814$

Sex: $F_{(1,16)}=4.536, p=0.0491^{*}$

Injury: $F_{(1,16)}=60.00, p<0.0001^{* * * *}$

Two-way ANOVA:

Sex $\times$ Injury: $F_{(1,16)}=0.4679, p=0.5038$

Sex: $F_{(1,16)}=1.147, p=0.3000$

Injury: $F_{(1,16)}=3.310, p=0.0876$

Two-way ANOVA:

Sex $\times$ Injury: $F_{(1,16)}=0.1846, p=0.6732$

Sex: $F_{(1,16)}=0.06028, p=0.8092$

Injury: $F_{(1,16)}=0.04463, p=0.8354$

Unpaired two-tailed $t$ test:

$t_{(16)}=0.9198, p=0.3713$

Unpaired two-tailed $t$ test:

$t_{(16)}=0.4229, p=0.6780$

Unpaired two-tailed $t$ test:

NF200: $t_{(10)}=0.8918, p=0.3934$

CGRP: $t_{(10)}=0.07865, p=0.9389$

IB4: $t_{(10)}=0.03361, p=0.9738$

Bonferroni multiple comparisons test:

Male, Contra vs Ipsi: $p=0.0005^{* * *}$

Female, Contra vs Ipsi: $p=0.0025^{* *}$

Bonferroni multiple comparisons test:

Male, Contra vs Ipsi: $p=0.0606$

Female, Contra vs Ipsi: $p=0.3250$

5 for each group

5 for each group

Bonferroni multiple comparisons test: Male, naive vs $56 \mathrm{~d}: p<0.0001^{* * * *}$

Female, naive vs $56 \mathrm{~d}: p=0.0029^{* *}$ naive, Male vs Female: $p=0.0492^{*}$ $56 \mathrm{~d}$, Male vs Female: $p>0.9999$

5 for each group

5 for each group

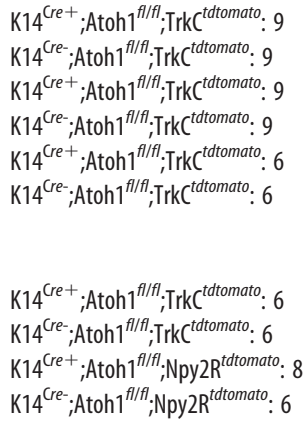

(Table continues.) 


\section{Table 1 Continued}

\begin{tabular}{|c|c|c|c|}
\hline Figure & Pre hoc & Post hoc & $N$ (number of samples/animals per group) \\
\hline $6 A$ & $\begin{array}{l}\text { Two-way ANOVA: } \\
\text { Force } \times \text { Genotype: } F_{(6,114)}=2.065, p=0.0627 \\
\text { Force: } F_{(3.101,58.92)}=61.53, p<0.0001^{* * * *} \\
\text { Genotype: } F_{(1,19)}=15.20, p=0.0010^{* * *}\end{array}$ & 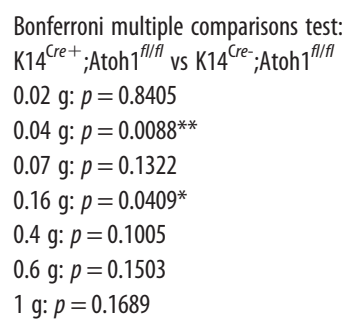 & 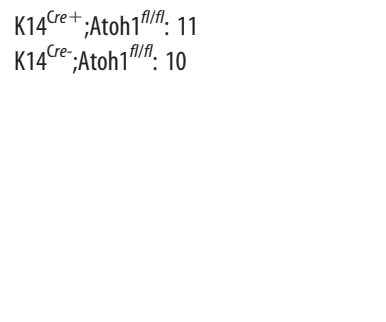 \\
\hline $6 B$ & $\begin{array}{l}\text { Two-way ANOVA: } \\
\text { Force } \times \text { Genotype: } F_{(6,114)}=1.536, p=0.1726 \\
\text { Force: } F_{(2.339,44.44)}=18.85, p<0.0001^{* * * *} \\
\text { Genotype: } F_{(1,19)}=8.225, p=0.0098^{* *}\end{array}$ & $\begin{array}{l}\text { Bonferroni multiple comparisons test: } \\
\text { K14 }{ }^{\text {Cre+ }} ; \text { Atoh } 1^{f / f l} \text { vs K1 } 14^{\text {Cre }} ; A \text { toh } 1^{f / f f l} \\
0.02 \mathrm{~g}: p=0.1577 \\
0.04 \mathrm{~g}: p=0.1566 \\
0.07 \mathrm{~g}: p=0.0803 \\
0.16 \mathrm{~g}: p=0.1203 \\
0.4 \mathrm{~g}: p=0.3648 \\
0.6 \mathrm{~g}: p=0.3138 \\
1 \mathrm{~g}: p=0.6102\end{array}$ & 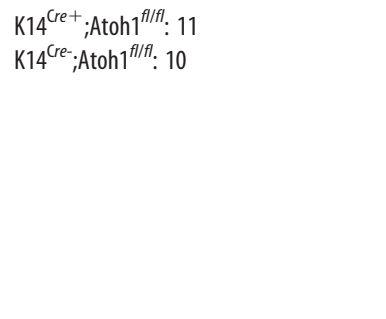 \\
\hline $6 C$ & $\begin{array}{l}\text { Two-way ANOVA: } \\
\text { Time } \times \text { Genotype: } F_{(5,95)}=2.753, p=0.0229^{*} \\
\text { Time: } F_{(3.544,67.33)}=14.26, p<0.0001^{* * * *} \\
\text { Genotype: } F_{(1,19)}=12.50, p=0.0022^{* *}\end{array}$ & 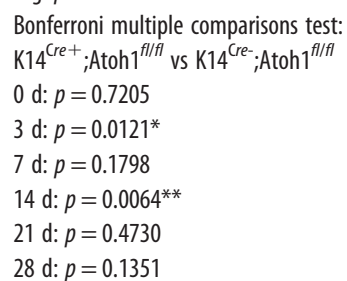 & 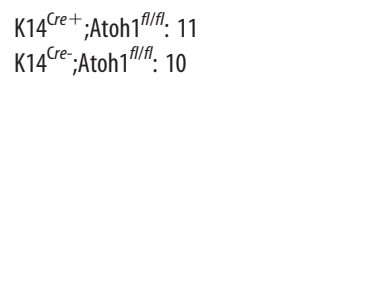 \\
\hline $6 D$ & $\begin{array}{l}\text { Two-way ANOVA: } \\
\text { Force } \times \text { Genotype: } F_{(6,120)}=3.545, p=0.0029^{* *} \\
\text { Force: } F_{(3.175,63.50)}=118.4, p<0.0001^{* * * *} \\
\text { Genotype: } F_{(1,20)}=2.407, p=0.1365\end{array}$ & & 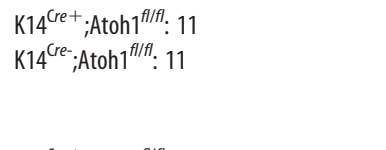 \\
\hline $6 E$ & $\begin{array}{l}\text { Two-way ANOVA: } \\
\text { Force } \times \text { Genotype: } F_{(6,120)}=4.346, p=0.0005^{* * *} \\
\text { Force: } F_{(1.998,39.96)}=29.07, p<0.0001^{* * * *} \\
\text { Genotype: } F_{(1,20)}=4.197, p=0.0538\end{array}$ & & 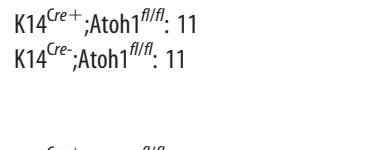 \\
\hline $6 F$ & $\begin{array}{l}\text { Two-way ANOVA: } \\
\text { Time } \times \text { Genotype: } F_{(5,100)}=1.933, p=0.0954 \\
\text { Time: } F_{(3.868,77.35)}=19.22, p<0.0001^{* * * *} \\
\text { Genotype: } F_{(1,20)}=9.820, p=0.0052^{* *}\end{array}$ & $\begin{array}{l}\text { Bonferroni multiple comparisons test: } \\
\text { K1 }^{\text {Gre+ }} ; \text { Atoh } 1^{f / f l} \text { vs K14 }{ }^{\text {Gre }} ; \text { Atoh } 1^{f / f l} \\
0 \mathrm{~d}: p=0.6235 \\
3 \mathrm{~d}: p=0.0582 \\
7 \mathrm{~d}: p=0.2048 \\
14 \mathrm{~d}: p=0.1786 \\
21 \mathrm{~d}: p=0.0666 \\
28 \mathrm{~d}: p=0.0845\end{array}$ & 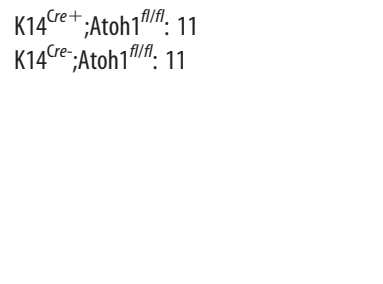 \\
\hline $6 G$ & $\begin{array}{l}\text { Two-way ANOVA: } \\
\text { Force } \times \text { Genotype: } F_{(7,154)}=0.9838, p=0.4452 \\
\text { Force: } F_{(3.754,82.58)}=97.02, p<0.0001^{* * * *} \\
\text { Genotype: } F_{(1,22)}=0.7751, p=0.3882\end{array}$ & & 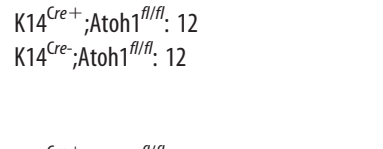 \\
\hline $6 H$ & $\begin{array}{l}\text { Two-way ANOVA: } \\
\text { Force } \times \text { Genotype: } F_{(7,154)}=6.136, p<0.0001^{* * * *} \\
\text { Force: } F_{(1.569,34.53)}=33.85, p<0.0001^{* * * *} \\
\text { Genotype: } F_{(1,22)}=6.292, p=0.0200^{*}\end{array}$ & 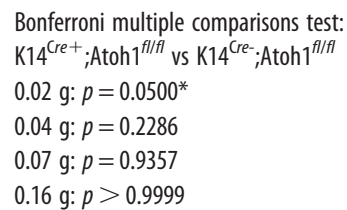 & 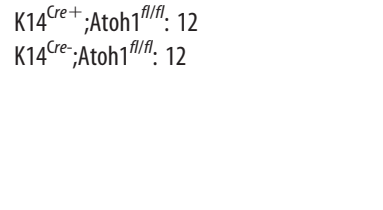 \\
\hline $6 /$ & $\begin{array}{l}\text { Two-way ANOVA: } \\
\text { Time } \times \text { Genotype: } F_{(5,110)}=1.413, p=0.2252 \\
\text { Time: } F_{(3.026,66.58)}=70.38, p<0.0001^{* * * *} \\
\text { Genotype: } F_{(1,22)}=11.02, p=0.0031^{* *}\end{array}$ & $\begin{array}{l}\text { Bonferroni multiple comparisons test: } \\
{\mathrm{K} 14^{\text {(re+ }} ; \text { Atoh }^{f / f l} \text { vs K14 }}^{\text {(re- }} ; \text { Atoh }^{\text {fl/fl }} \\
0 \mathrm{~d}: p=0.3000 \\
3 \mathrm{~d}: p=0.0507 \\
7 \mathrm{~d}: p=0.1668 \\
14 \mathrm{~d}: p=0.0867 \\
21 \mathrm{~d}: p=0.0175^{*} \\
28 \mathrm{~d}: p=0.0375^{*}\end{array}$ & 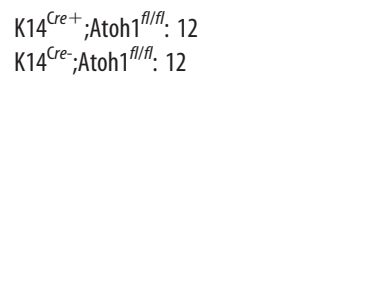 \\
\hline
\end{tabular}




\section{Table 1 Continued}

\begin{tabular}{ll}
\hline Figure & Pre hoc \\
\hline $6 J$ & Two-way ANOVA: \\
& Force $\times$ Genotype: $F_{(6,114)}=3.021, p=0.0089^{* *}$ \\
& Force: $F_{(4.031,76.59)}=72.52, p<0.0001^{* * * *}$ \\
& Genotype: $F_{(1,19)}=6.657, p=0.0183^{*}$ \\
& \\
& \\
$6 K$ & Two-way ANOVA: \\
& Force $\times$ Genotype: $F_{(6,114)}=4.483, p=0.0004^{* * *}$ \\
& Force: $F_{(2.729,51.84)}=17.51, p<0.0001^{* * * *}$ \\
& Genotype: $F_{(1,19)}=4.508, p=0.0471^{*}$
\end{tabular}

Two-way ANOVA:

Time $\times$ Genotype: $F_{(5,95)}=2.362, p=0.0456^{*}$ Time: $F_{(3.763,71.50)}=32.01, p<0.0001^{* * * *}$ Genotype: $F_{(1,19)}=5.763, p=0.0268^{*}$
Post hoc

Bonferroni multiple comparisons test:

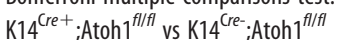

$0.02 \mathrm{~g}: p>0.9999$

$0.04 \mathrm{~g}: p>0.9999$

$0.07 \mathrm{~g}: p=0.1098$

$0.16 \mathrm{~g}: p=0.1903$

$0.4 \mathrm{~g}: p=0.1224$

$0.6 \mathrm{~g}: p>0.9999$

$1 \mathrm{~g}: p>0.9999$

Bonferroni multiple comparisons test:

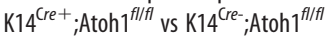

$0.02 \mathrm{~g}: p=0.1144$

$0.04 \mathrm{~g}: p=0.1314$

$0.07 \mathrm{~g}: p=0.2376$

$0.16 \mathrm{~g}: p>0.9999$

$0.4 \mathrm{~g}: p>0.9999$

$0.6 \mathrm{~g}: p>0.9999$

$1 \mathrm{~g}: p>0.9999$

Bonferroni multiple comparisons test: $\mathrm{K} 14^{\mathrm{Cre}+} ; \mathrm{Atoh}^{\mathrm{fl/fl}}$ vs $\mathrm{K} 14^{\mathrm{Cree}} ; \mathrm{Atoh}^{\mathrm{fl} / \mathrm{fl}}$

$0 \mathrm{~d}: p>0.9999$

$3 \mathrm{~d}: p=0.3300$

$7 \mathrm{~d}: p=0.0981$

$14 \mathrm{~d}: p>0.9999$

$21 \mathrm{~d}: p=0.3422$

$28 \mathrm{~d}: p=0.0981$

Bonferroni multiple comparisons test $\mathrm{K}_{1}{ }^{\mathrm{Cre+}} ; \mathrm{Atoh}^{\mathrm{fl} / \mathrm{fl}}$ vs K14${ }^{\mathrm{Cre}-}$;Atoh ${ }^{\text {fl/ff }}$

$0 \mathrm{~d}: p>0.9999$

$3 \mathrm{~d}: p=0.1218$

$7 \mathrm{~d}: p=0.0531$

$14 \mathrm{~d}: p=0.0300^{*}$

$21 \mathrm{~d}: p=0.0182^{*}$

$28 \mathrm{~d}: p=0.0036^{* *}$

Bonferroni multiple comparisons test

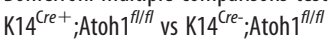

$0 \mathrm{~d}: p=0.2213$

$3 \mathrm{~d}: p=0.3591$

$7 \mathrm{~d}: p=0.2636$

$14 \mathrm{~d}: p=0.0280^{*}$

$21 \mathrm{~d}: p=0.0376^{*}$

$28 \mathrm{~d}: p=0.0097^{* *}$

Bonferroni multiple comparisons test

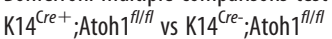

$0 \mathrm{~d}: p>0.9999$

$3 \mathrm{~d}: p=0.3348$

$7 \mathrm{~d}: p=0.2794$

$14 \mathrm{~d}: p=0.4035$

$21 \mathrm{~d}: p=0.2362$

$28 \mathrm{~d}: p=0.1361$

Bonferroni multiple comparisons test

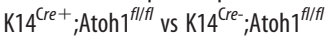

$0 \mathrm{~d}: p=0.9190$

$3 \mathrm{~d}: p=0.1816$

$7 \mathrm{~d}: p=0.4996$

$14 \mathrm{~d}: p=0.3343$

$21 \mathrm{~d}: p=0.2900$

$28 \mathrm{~d}: p=0.0949$
$N$ (number of samples/animals per group)

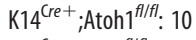
K14 ${ }^{\text {(re } ; A t o h 1^{f / f l f l}:} 11$

$\mathrm{K}^{\mathrm{Cre+}} \mathrm{Atoh}^{\mathrm{fl/ff}:}: 10$

$\mathrm{K} 14^{\mathrm{Cre}} ; \mathrm{Atoh}^{\mathrm{fl} / \mathrm{fl}}: 11$

$\mathrm{K}^{\mathrm{Cre+}}{ }^{\mathrm{Cre}}$ Atoht $1^{\mathrm{flfff}:}: 10$

$\mathrm{K} 14^{\mathrm{Cre}-} ; \mathrm{Atoh}^{\mathrm{fl} / \mathrm{fl}:}: 11$

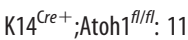

K14 ${ }^{\text {Cree } ; A t o h 1^{f / f / f l}: 10}$

$\mathrm{K}_{1} 4^{\mathrm{Cre}+} ; \mathrm{Atoh}^{\mathrm{fl} / \mathrm{fl}}: 11$ $\mathrm{K} 14^{\mathrm{Cre}} ; \mathrm{Atoh}^{\mathrm{fl} / \mathrm{fl}}: 10$

$\mathrm{K}^{\mathrm{Cre+}} \mathrm{Atoh}^{\mathrm{fl/ff}:}: 11$ $\mathrm{K} 14^{\mathrm{Cre}} ; \mathrm{Atoh}^{\mathrm{fl} / \mathrm{fl}:}: 11$

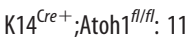
$\mathrm{K}^{\mathrm{Cre}}{ }^{\mathrm{Cr}} ; \mathrm{Atoh}^{\mathrm{fl} / \mathrm{fl}:}: 11$

$\mathrm{K}^{\mathrm{Cre+}} 4^{\mathrm{ret}}$ Atoh $1^{\mathrm{fl/f}:}: 12$ K14 ${ }^{\text {(ree }}$;Atoh $1^{\text {flffl: }}: 12$ 


\section{Table 1 Continued}

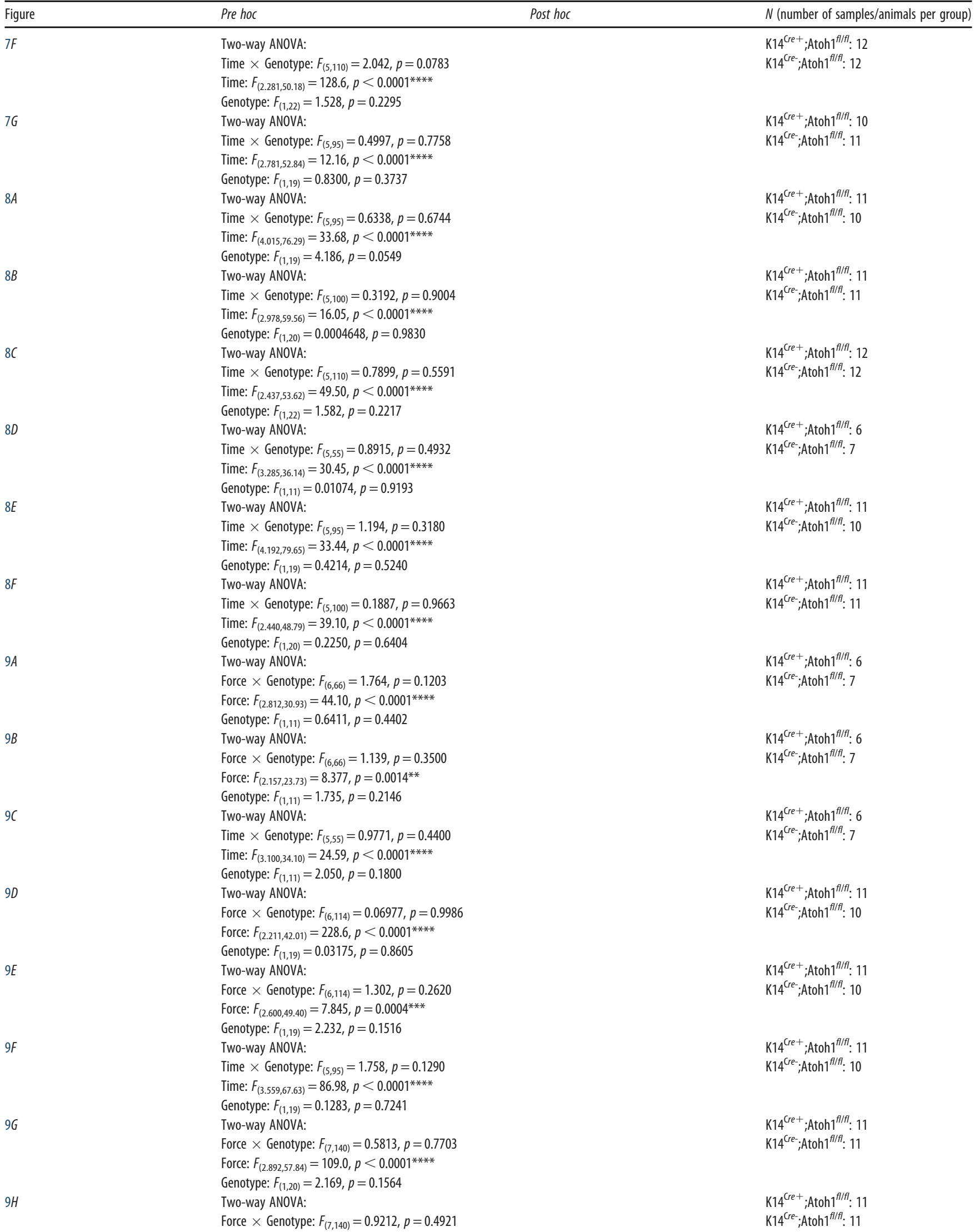

Force: $F_{(1,368,27.37)}=24.42, p<0.0001^{* * * *}$

Genotype: $F_{(1,20)}=0.03053, p=0.8630$ 


\section{Table 1 Continued}

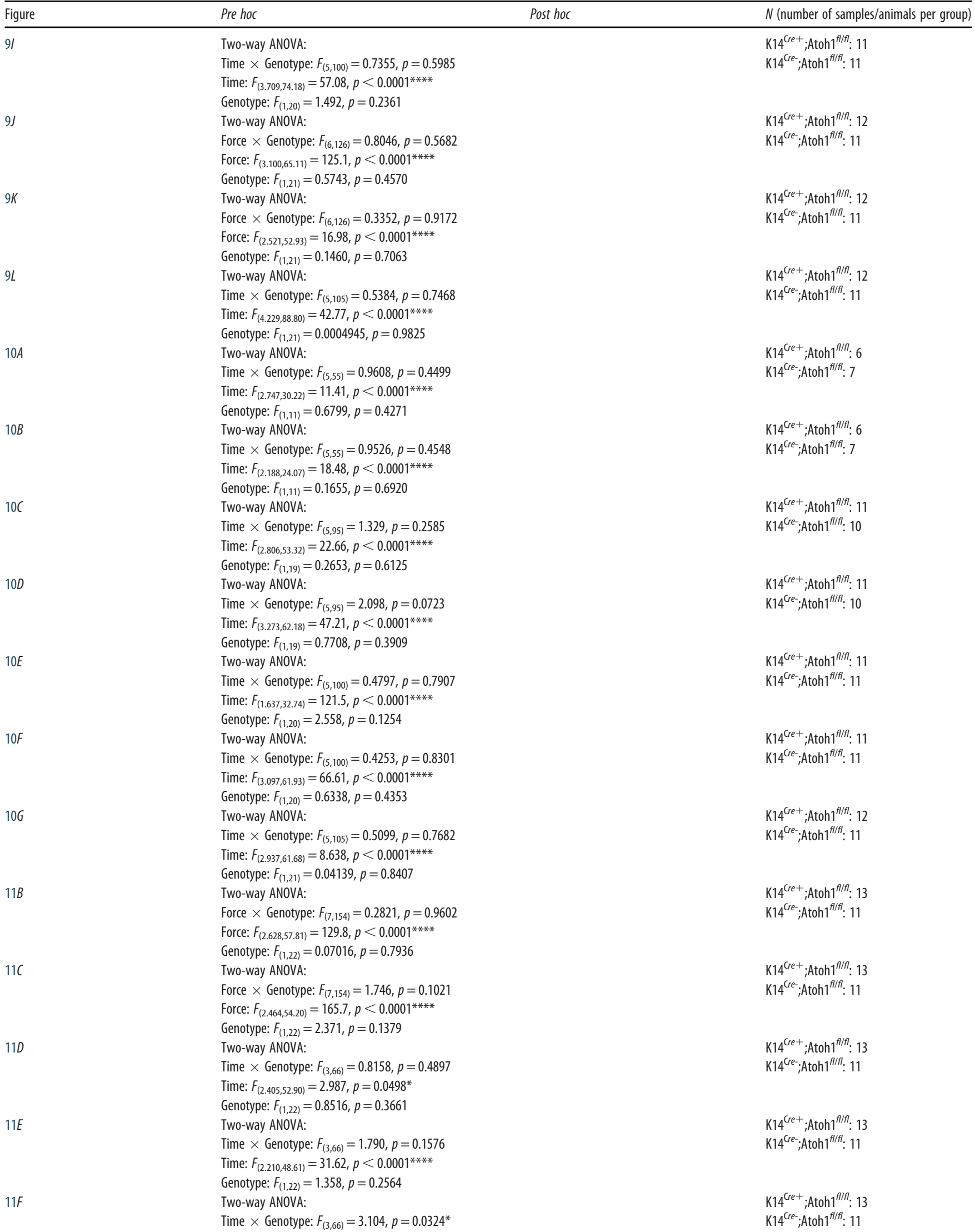

Time: $F_{(2.273,50.00)}=131.0, p<0.0001^{* * *}$

K14 ${ }^{\text {Cre- }}$; Atoh $1^{f / f f l}: 11$ 
Table 1 Continued

\begin{tabular}{|c|c|c|c|}
\hline Figure & Pre hoc & Post hoc & $N$ (number of samples/animals per group) \\
\hline $11 G$ & $\begin{array}{l}\text { Two-way ANOVA: } \\
\text { Time } \times \text { Genotype: } F_{(3,66)}=0.5619, p=0.6421 \\
\text { Time: } F_{(2.708,59.58)}=29.72, p<0.0001^{* * * *} \\
\text { Genotype: } F_{(1,22)}=0.3310, p=0.5709\end{array}$ & & 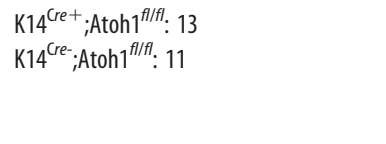 \\
\hline $11 H$ & $\begin{array}{l}\text { Paired two-tailed } t \text { test: } \\
t_{(4)}=0.04563, p=0.9658\end{array}$ & & Contra/lpsi: 5 \\
\hline Extended Data Fig. 7-1A & $\begin{array}{l}\text { Two-way ANOVA: } \\
\text { Force } \times \text { Genotype: } F_{(6,372)}=5.365, p<0.0001^{* * * *} \\
\text { Force: } F_{(4.151,257.4)}=227.7, p<0.0001^{* * * *} \\
\text { Genotype: } F_{(1,62)}=18.29, p<0.0001^{* * * *}\end{array}$ & 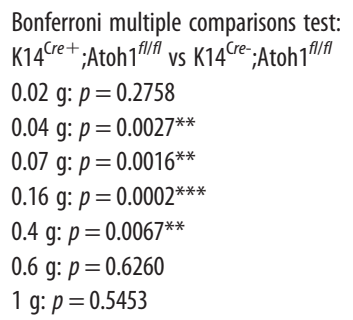 & 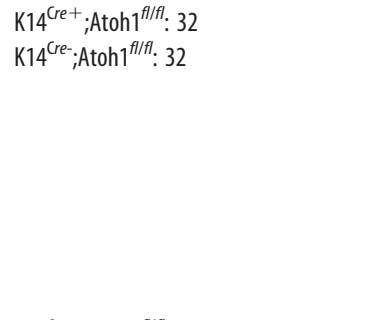 \\
\hline Extended Data Fig. 7-1B & $\begin{array}{l}\text { Two-way ANOVA: } \\
\text { Force } \times \text { Genotype: } F_{(6,372)}=8.692, p<0.0001^{* * * *} \\
\text { Force: } F_{(2.545,157.8)}=62.96, p<0.0001^{* * * *} \\
\text { Genotype: } F_{(1,62)}=17.73, p<0.0001^{* * * *}\end{array}$ & 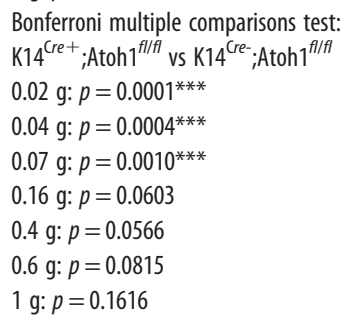 & 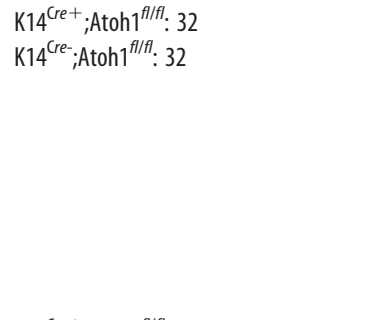 \\
\hline Extended Data Fig. 7-1C & $\begin{array}{l}\text { Two-way ANOVA: } \\
\text { Time } \times \text { Genotype: } F_{(5,310)}=5.751, p<0.0001^{* * * *} \\
\text { Time: } F_{(4.383,271.7)}=62.56, p<0.0001^{* * * *} \\
\text { Genotype: } F_{(1,62)}=28.54, p<0.0001^{* * * *}\end{array}$ & 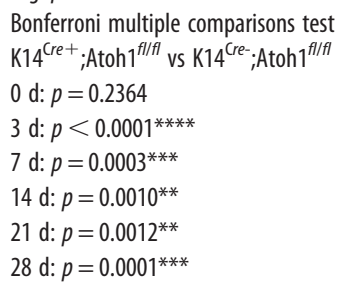 & 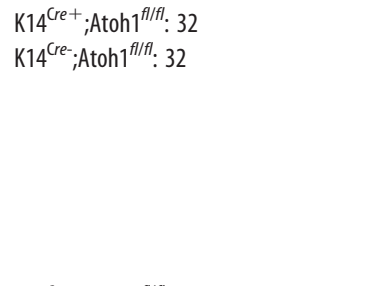 \\
\hline Extended Data Fig. 7-1D & $\begin{array}{l}\text { Two-way ANOVA: } \\
\text { Time } \times \text { Genotype: } F_{(5,310)}=3.217, p=0.0076^{* *} \\
\text { Time: } F_{(3.433,212.9)}=43.18, p<0.0001^{* * * *} \\
\text { Genotype: } F_{(1,62)}=13.09, p=0.0006^{* * *}\end{array}$ & $\begin{array}{l}\text { Bonferroni multiple comparisons test } \\
\text { K1 } 1^{\text {Cre+ }} ; \text { Atoh } 1^{f / f f} \text { vs K1 } 14^{\text {Cre }} ; \text { Atoh } 1^{f l / f l} \\
0 \mathrm{~d}: p=0.1901 \\
3 \mathrm{~d}: p=0.0406^{*} \\
7 \mathrm{~d}: p=0.0021^{* *} \\
14 \mathrm{~d}: p=0.0126^{*} \\
21 \mathrm{~d}: p=0.0166^{*} \\
28 \mathrm{~d}: p=0.0077^{* *}\end{array}$ & 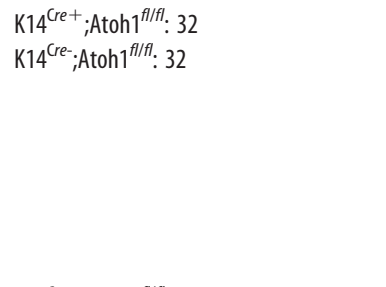 \\
\hline Extended Data Fig. 7-1E & $\begin{array}{l}\text { Two-way ANOVA: } \\
\text { Time } \times \text { Genotype: } F_{(5,205)}=2.975, p=0.0129^{*} \\
\text { Time: } F_{(3.831,157.1)}=35.77, p<0.0001^{* * * *} \\
\text { Genotype: } F_{(1,41)}=17.27, p=0.0002^{* * *}\end{array}$ & $\begin{array}{l}\text { Bonferroni multiple comparisons test } \\
\text { K1 } 4^{\text {Cre+ }} ; \text { Atoh } 1^{f / f f} \text { vs K14 } 4^{\text {Cree }} ; \text { Atoh } 1^{f l / f l} \\
0 \mathrm{~d}: p=0.0710 \\
3 \mathrm{~d}: p=0.0209^{*} \\
7 \mathrm{~d}: p=0.0406^{*} \\
14 \mathrm{~d}: p=0.0041^{* *} \\
21 \mathrm{~d}: p=0.0057^{* *} \\
28 \mathrm{~d}: p=0.0005^{* * *}\end{array}$ & 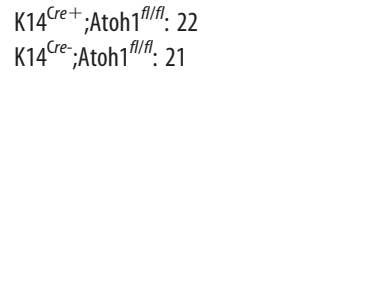 \\
\hline Extended Data Fig. 7-1F & $\begin{array}{l}\text { Two-way ANOVA: } \\
\text { Force } \times \text { Genotype: } F_{(6,516)}=3.720, p=0.0012^{* *} \\
\text { Force: } F_{(4.042,347.6)}=303.6, p<0.0001^{* * * *} \\
\text { Genotype: } F_{(1,86)}=16.28, p=0.0001^{* * *}\end{array}$ & 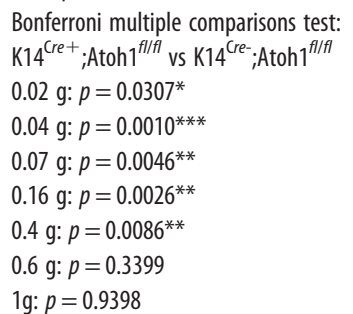 & 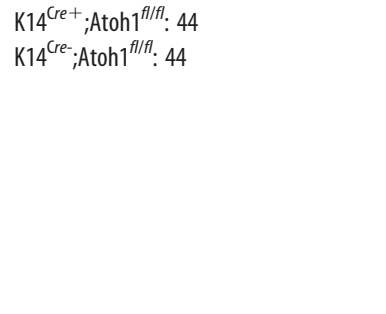 \\
\hline
\end{tabular}




\section{Table 1 Continued}

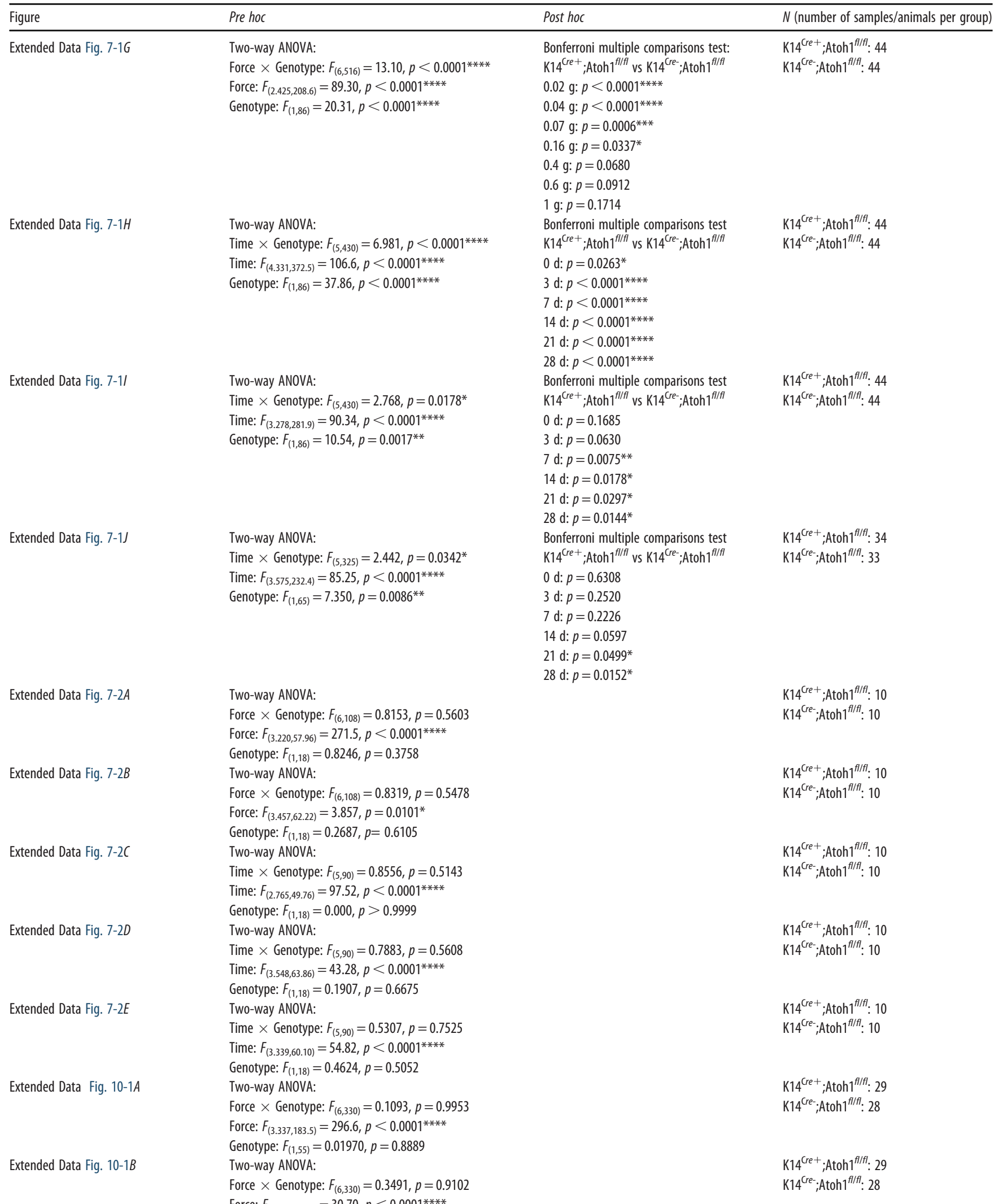


Table 1 Continued

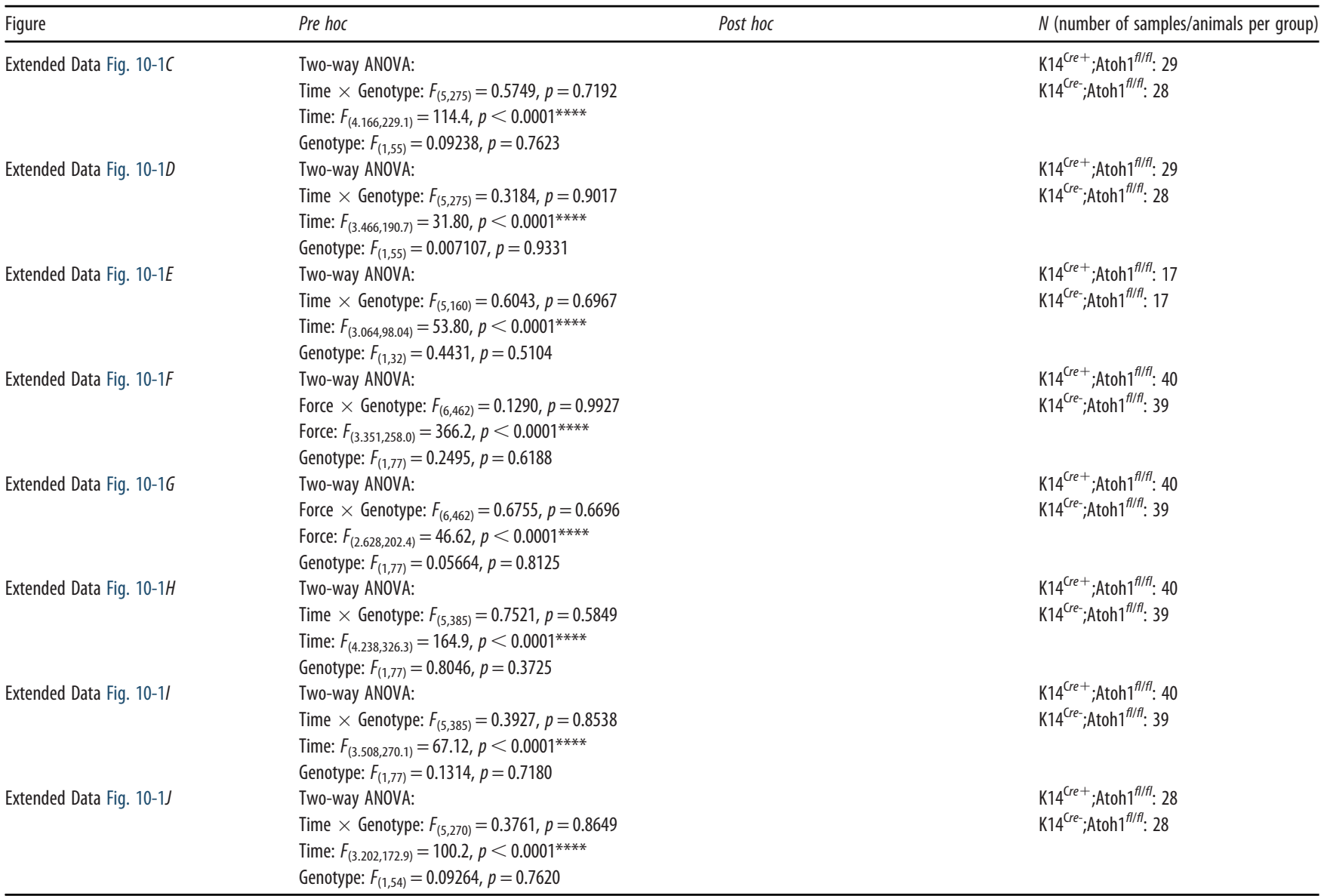

Asterisks indicated signifcant differences at levels of $* p<0.05, * * p<0.01, * * * p<0.001$, and $* * * * p<0.0001$.

with anti-K17, which labels hair follicles and the specialized subpopulation of keratinocytes that give rise to Merkel cells (McGowan and Coulombe, 1998; Doucet et al., 2013), and with anti-neurofilament heavy chain (NF200), to visualize myelinated sensory nerve fibers. In the hairy skin surrounding the plantar territory (Fig. 1A, Domain 1; Fig. 1B), Merkel cells were observed in small clusters located adjacent to a subset of $\mathrm{K} 7^{+}$hair follicles (presumably guard hair follicles), and often in close proximity to $\mathrm{NF}_{200}{ }^{+}$fibers (Fig. 1B, inset a), as previously described for hairy skin (Halata et al., 2003). In the glabrous skin proximal to the foot pads (Fig. 1A, Domain 2; Fig. $1 B$ ), Merkel cells were sparsely distributed, individually or in groups of 2 or 3 , without an obvious pattern of organization. They tended to be more common near the paw midline than in more medial and lateral regions (Fig. $1 A$, $B)$. Most Merkel cells in this domain were in close proximity to $\mathrm{NF} 200^{+}$afferent terminals, and nearly all were also juxtaposed to small clusters of strongly $\mathrm{K}^{+} 7^{+}$keratinocytes (Fig. $1 B$, inset b). While the K17 antibody occasionally labeled a subset of the Merkel cells, as well as scattered, individual keratinocytes, the Merkel cell-associated clusters were distinct with respect to their contiguousness with Troma-1-positive Merkel cells, and likely represent the glabrous skin equivalent of touch domes found in hairy skin. In the foot pads (Fig. 1A, Domain 3; Fig. 1C), as previously described (Moll et al., 1996; Doucet et al., 2013), Merkel cells were found in dense clusters. In this region, they were consistently associated with corresponding clusters of $\mathrm{K}^{+} 7^{+}$keratinocytes and occasionally in proximity to $\mathrm{NF}_{200^{+}}$afferents, although the quality of whole-mount staining for the latter two markers was suboptimal in the foot pads. Immunostaining of transverse skin sections confirmed the basal epidermal localization of Merkel cells (Fig. $1 E$ ). We also looked for Merkel cells in hind paw plantar skin hair follicles (Fig. 1A, Domain 4; Fig. 1D). Consistent with the prior characterization of these follicles (Walcher et al., 2018), we observed $77 \pm 4$ (mean \pm SEM) hair follicles per hind paw $(n=4)$. In that study, it was proposed that these follicles were innervated predominantly by A $\delta$ RA LTMRs and circumferential endings. However, $30 \pm 7$ (mean \pm SEM, 39.6\%) of the hair follicles we analyzed were associated with Merkel cell clusters (Fig. $1 A, D, G$ ), and these were often in close approximation to NF200 ${ }^{+}$afferents (Fig. 1D,F). No hair follicles were observed in the plantar skin of the front paws (data not shown). Finally, we stained for Merkel cells in Trk $C^{\text {tdtomato }}$ mice, in whose skin A $\beta$ SAI LTMRs, as well as A $\beta$ Field-LTMR circumferential endings, and a subset of free nerve endings are labeled (Bai et al., 2015). This approach afforded us the opportunity to label a more restricted population of neurons than could be achieved with antiNF200. We observed a close approximation of Merkel cells to tdTomato-labeled terminals, presumably A $\beta$ SAI LTMRs, in all four skin areas (Fig. $1 H-J$ ). Thus, Merkel cells are located in each of the four major domains of the plantar mouse paw skin and adjacent hairy skin.

\section{Differential effects of nerve injury on distinct hind paw Merkel cell populations}

Previous studies involving multiple mammalian species have defined a heterogeneous pattern of changes in Merkel cell 
A

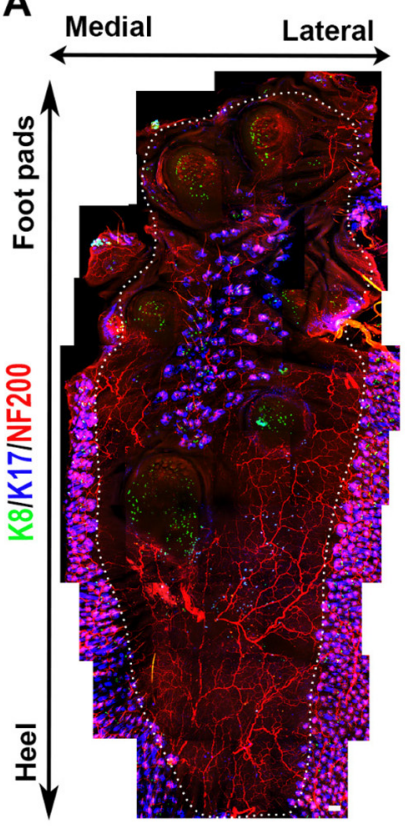

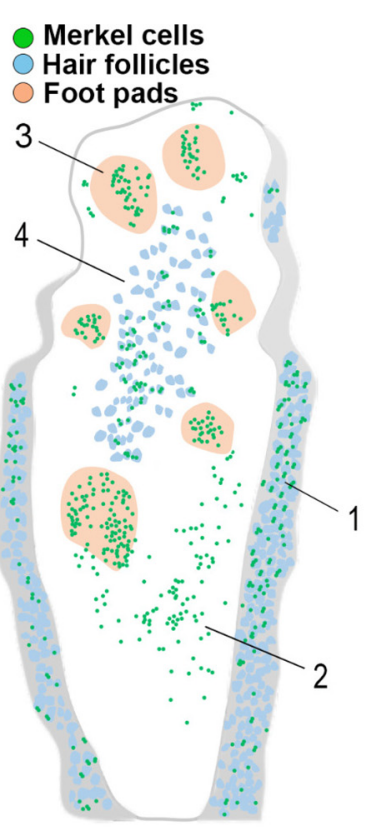

Hair follicles Foot pads

2
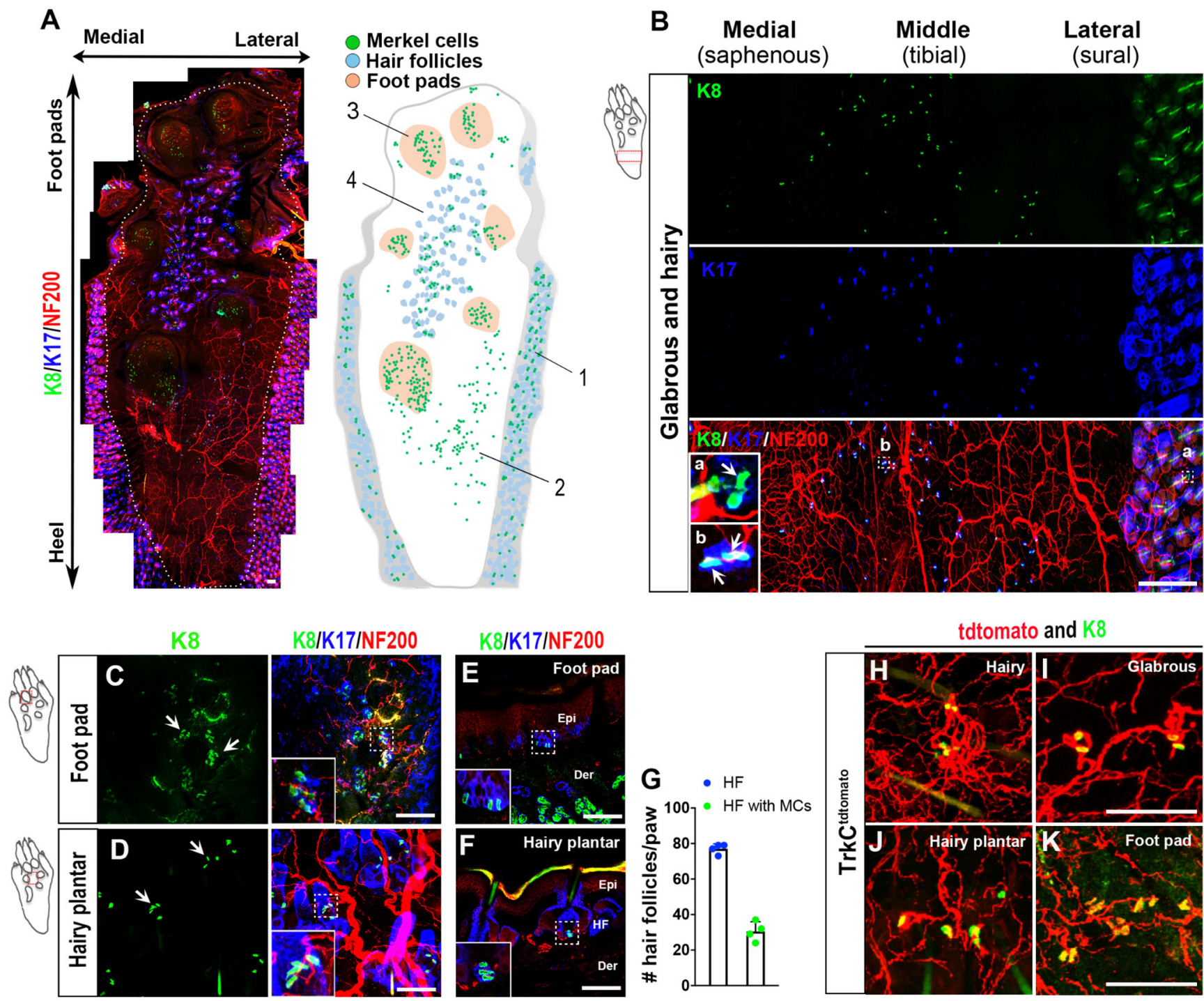

Figure 1. Merkel cell expression pattern in hind paw skin. A, Whole-mount immunostaining for K8 (green), K17 (blue), and NF200 (red) in mouse hind paw (left). White dashed line indicates the boundary between plantar skin and adjacent hairy skin. Schematic map (right) shows location of Merkel cells (green), foot pads (tan), and hair follicles (gray) in the specimen at left. Domains 1-4 of the hind paw are defined in the text. Scale bar, $100 \mu \mathrm{m}$. B. Whole-mount immunostaining for K8 (green), K17 (blue), and NF200 (red) in glabrous skin proximal to the foot pads and in adjacent hairy skin. $\boldsymbol{B} \boldsymbol{a}, \boldsymbol{B} \boldsymbol{b}$ (Insets), Higher-magnification views of areas from hairy and glabrous skin, respectively, indicated by dashed boxes. Arrows indicate $\mathrm{K}^{+}{ }^{+}$Merkel cell cluster in hairy skin and individual $\mathrm{K}^{+}$Merkel cells in glabrous skin, respectively. Note the close relationship in glabrous skin between Merkel cells and small clusters of K17 ${ }^{+}$epidermal cells. Scale bar, $500 \mu \mathrm{m}$. C, D, Whole-mount immunostaining for K8 (green), K17 (blue), and NF200 (red) in foot pads (C) and hairy plantar skin (D). Arrows indicate K8 ${ }^{+}$Merkel cell clusters. Insets, Higher-magnification views of the areas indicated by dashed boxes. Scale bar, $100 \mu \mathrm{m} . \boldsymbol{E}, \boldsymbol{F}$, Immunostaining for K8 (green), K17 (blue), and NF200 (red) on transverse sections of hind paw foot pads $(\boldsymbol{E})$ and hairy plantar skin $(\boldsymbol{F})$. Insets, Higher-magnification view of $\mathrm{K}^{+}$Merkel cells at epidermal-dermal border of glabrous skin and in the hair follicles of hairy skin, respectively, in areas outlined by dashed boxes. Epi, Epidermis; Der, dermis; HF, hair follicle. Scale bar, $100 \mu \mathrm{m}$. G, Quantification of the number of total K17 ${ }^{+}$hair follicles per hind paw in plantar hairy skin and the number of $\mathrm{K}^{+} 7^{+}$hair follicles per hind paw associated with $\mathrm{K}^{+}$Merkel cells $(n=4)$. Data are mean \pm SEM. $\boldsymbol{H}-\boldsymbol{K}$, In TrkCtomato mice, whole-mount immunostaining for K8 (green) and tdTomato (red) in the hairy skin $(\boldsymbol{H})$, glabrous skin $(\boldsymbol{I})$, hairy plantar skin $(\boldsymbol{I})$, and foot pad $(\boldsymbol{K})$ of the hind paw. Scale bar, $100 \mu \mathrm{m}$.

abundance following skin denervation, depending on the skin location assayed and whether reinnervation was allowed to occur (English et al., 1983; Nurse and Diamond, 1984; Nurse et al., 1984a; Mills et al., 1989; Xiao et al., 2015; Ko et al., 2016). To examine this issue in a model of peripheral nerve injury associated with neuropathic pain, we performed SNI surgery, in which two branches of the sciatic nerve, the common peroneal and tibial nerves, are severed, while the sural branch, which innervates the plantar and hairy skin of the lateral hind paw, is spared (Fig. 2A) (Decosterd and Woolf, 2000; Shields et al., 2003; Bourquin et al., 2006). We initially examined the spatial distribution of $\mathrm{K}^{+}$Merkel cells and NF200 ${ }^{+}$myelinated afferent nerve terminals in different paw skin areas after nerve injury in male mice, using the contralateral hind paw as a control (Fig. 2B-E). As expected, after injury, in the glabrous skin proximal to the foot pads, we observed an ipsilateral reduction in immunostaining for $\mathrm{NF}_{200}{ }^{+}$nerve fibers that was most prominent in the middle of the paw, a territory innervated by the severed tibial nerve, but that appeared to recover over time, presumably through collateral sprouting. Following denervation, we also observed a reduction in Merkel cells in the ipsilateral glabrous hind paw skin of WT mice, both as compared over time and relative to the contralateral paw, that reached statistical significance at day 28 and persisted at day 56 (Fig. 2B-F). We were unable to evaluate potential injury induced changes in Merkel cell density in the sural nerveinnervated portion of the hind paw glabrous skin because of its 


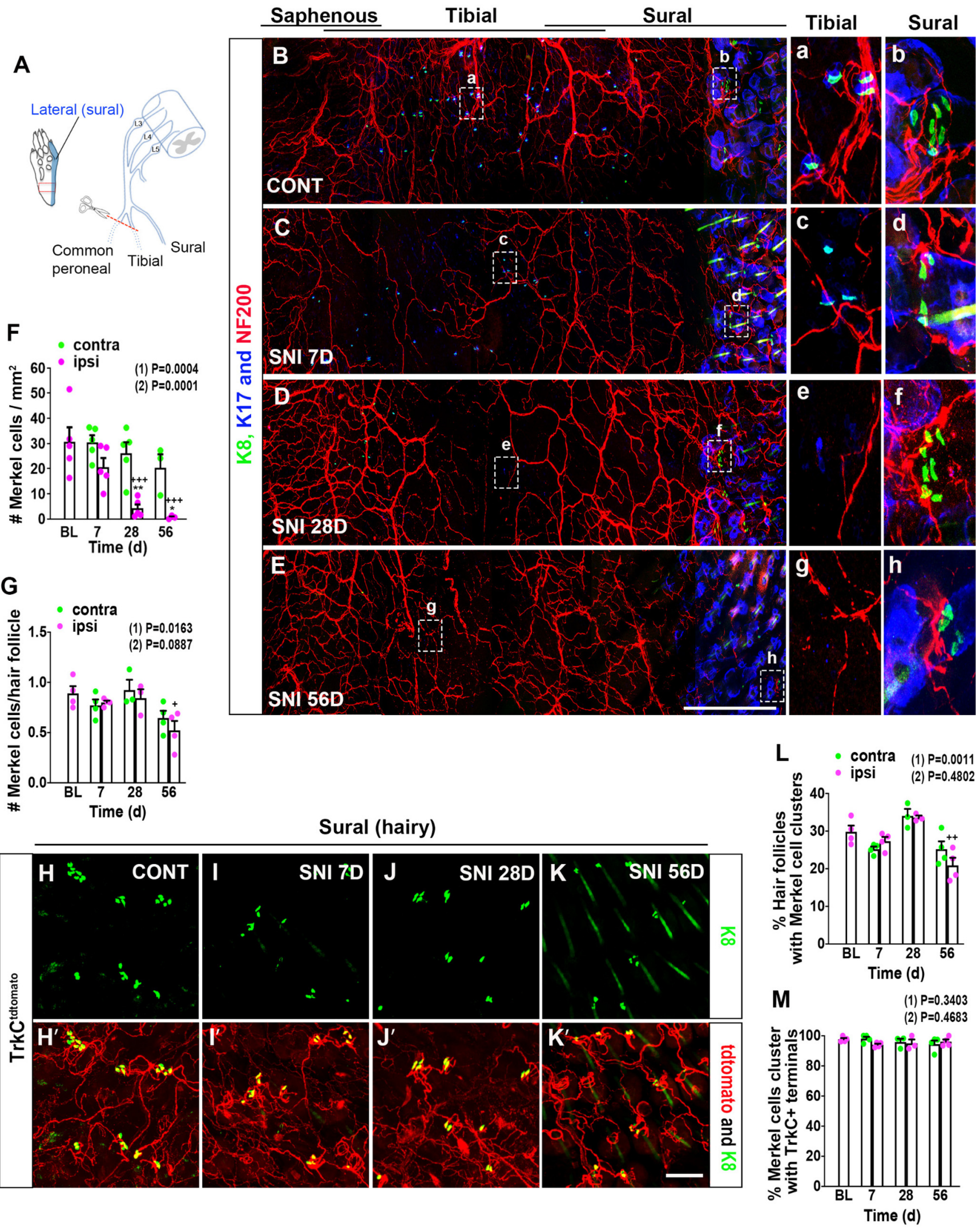

Figure 2. Abundance and distribution of hind paw Merkel cells and associated nerve endings in male mice after peripheral nerve injury. $A$, Schematic diagram of SNI injury model, showing the three branches of the sciatic nerve (common peroneal, tibial, and sural) and the lateral plantar area (blue) of hind paw innervated by sural afferents. Red box represents area examined further in $\boldsymbol{B}$-E. B-E, Whole-mount immunostaining for K8 (green), K17 (blue), and NF200 (red) on the contralateral (B) and ipsilateral (C) hind paw on day 7, and ipsilateral hind paw on day 28 $(\boldsymbol{D})$ and $56(\boldsymbol{E})$ after SNI surgery. Right, Insets, Amplified views of the areas of the middle (tibial nerve innervation territory; $\boldsymbol{a}, \boldsymbol{c}, \boldsymbol{e}$, and $\boldsymbol{g}$ ) and hairy lateral (sural nerve innervation territory; $\boldsymbol{b}$, $\boldsymbol{d}, \boldsymbol{f}$, and $\boldsymbol{h}$ ) areas of hind paw, respectively, indicated by the dashed boxes. Scale bar, $500 \mu \mathrm{m}$. $\boldsymbol{F}$, Quantification of Merkel cell numbers in contralateral (green) and ipsilateral (magenta) hind paw plantar skin (proximal to foot pads) at the indicated times after SNI $(n=3-5)$. BL, Baseline. G, Quantification of the mean number of Merkel cells per hair follicle in the lateral hairy skin 

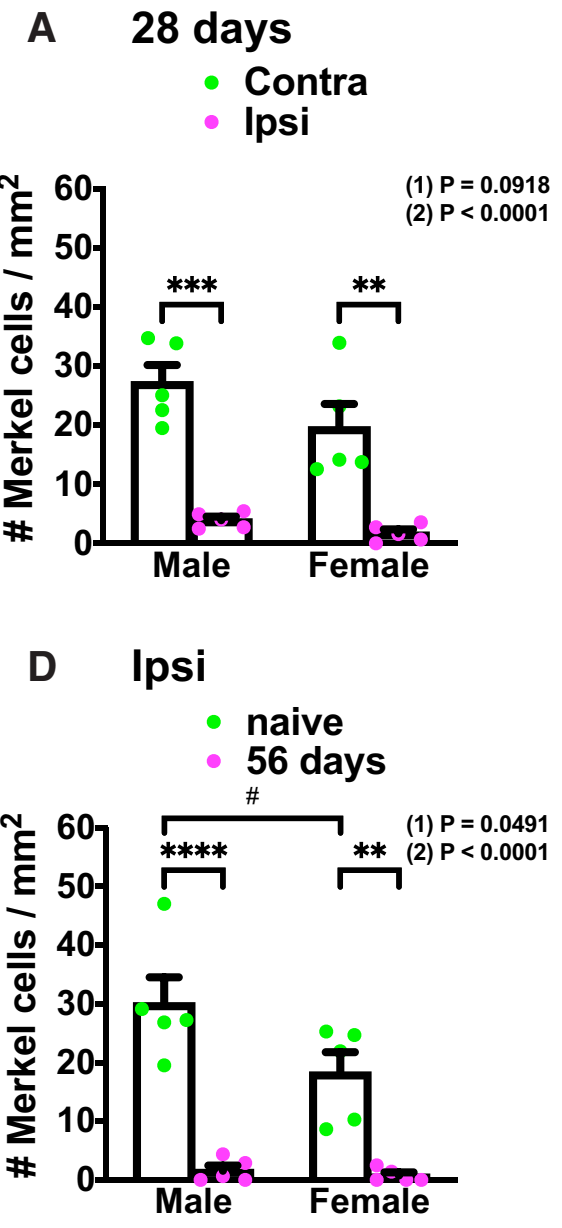

B

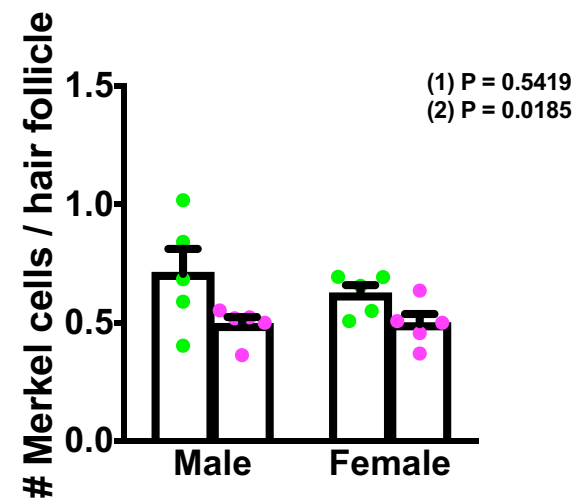

E

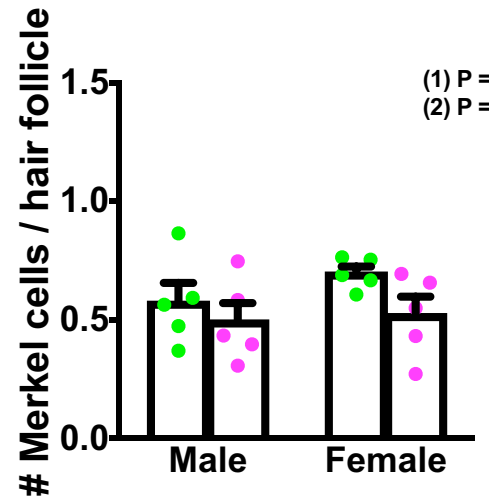

C

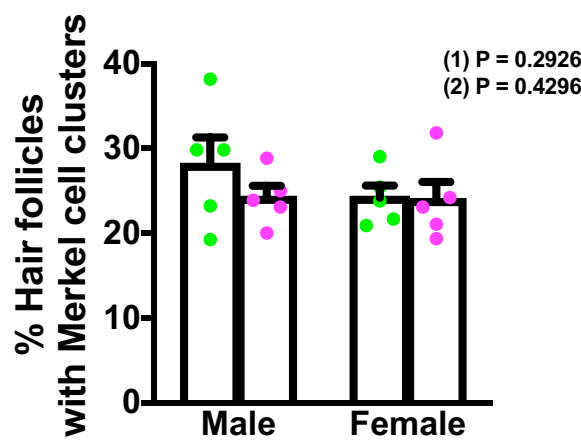

$\mathbf{F}$

Figure 3. Merkel cell abundance and distribution comparison in male and female mice before and after nerve injury. $A$, Quantification of Merkel cell density in contralateral (green) and ipsilateral (magenta) hind paw plantar skin (proximal to foot pads) in males and females at $28 \mathrm{~d}$ after SNI $(n=5)$. $\boldsymbol{B}$, Quantification of the mean number of Merkel cells per hair follicle in the lateral hairy skin of the contralateral (green) and ipsilateral (magenta) hind paw in males and females at $28 \mathrm{~d}$ after SNI $(n=5)$. C, Quantification of the percentage of hair follicles associated with Merkel cells in the lateral hairy skin of the contralateral (green) and ipsilateral (magenta) hind paw in males and females at $28 \mathrm{~d}$ after SNI $(n=5)$. D, Quantification of Merkel cell density in naive (green) and SNI day 56 (magenta) ipsilateral hind paw plantar skin (proximal to foot pads) in males and females $(n=5)$. $\boldsymbol{E}$, Quantification of the mean number of Merkel cells per hair follicle in the lateral hairy skin of the naive (green) and SNI day 56 (magenta) ipsilateral hind paw in males and females $(n=5)$. $\boldsymbol{F}$, Quantification of the percentage of hair follicles associated with Merkel cells in the lateral hairy skin of the naive (green) and SNI day 56 (magenta) ipsilateral hind paw in males and females ( $n=5$ ). Data are mean \pm SEM. (1) Overall $p$ value for difference between males and females using two-way ANOVA. Results of Bonferroni post hoc correction: ${ }^{\sharp} p<0.05$. (2) $\boldsymbol{A}-\boldsymbol{C}$, Overall $p$ value for difference between ipsilateral and contralateral paws using two-way ANOVA. $\boldsymbol{D}-\boldsymbol{F}$, Overall $p$ value for difference between naive and SNI day 56 ipsilateral paws using two-way ANOVA. Results of Bonferroni $p o s t$ hoc correction: ${ }^{*} p<0.05$; ${ }^{* *} p<0.01 ;{ }^{* *} p<0.001 ;{ }^{* * * *} p<0.0001$.

\footnotetext{
of the contralateral (green) and ipsilateral (magenta) hind paw after SNI ( $n=3$ or 4). $\boldsymbol{H}-\boldsymbol{K}$, In Trk Cdtomato mice, whole-mount immunostaining for K8 (green) and tdTomato (red) in the hairy lateral area of contralateral $\left(\boldsymbol{H}, \boldsymbol{H}^{\prime}\right)$ and ipsilateral $\left(\boldsymbol{I}, \boldsymbol{I}^{\prime}\right)$ hind paws on day 7 , and ipsilateral hind paw on day $28\left(\boldsymbol{J} \boldsymbol{J}^{\prime}\right)$ and day $56\left(\boldsymbol{K}, \boldsymbol{K}^{\prime}\right)$ after SNI. Insets, Merkel cells associated with TrkC ${ }^{\text {tdtomato+ }}$ nerve endings. Scale bar, $100 \mu \mathrm{m}$. L, Quantification of the percentage of hair follicles associated with Merkel cells in the lateral hairy skin of the contralateral (green) and ipsilateral (magenta) hind paws after SNI ( $n=3$ or 4). M, Quantification of the percentage of $\mathrm{K}^{+}$Merkel cell clusters in close proximity to Trk ${ }^{\text {tdtomato+ }}$ nerve endings in the lateral hairy skin of the contralateral (green) and ipsilateral (magenta) hind paws after SNI $(n=3$ or 4 ). Data are mean \pm SEM. (1) Overall $p$ value from one-way ANOVA of ipsilateral paw data over time. Results of Bonferroni post hoc correction: ${ }^{+} p<0.05 ;{ }^{++} p<0.01$; ${ }^{+++} p<0.001$. (2) Overall $p$ value for difference between ipsilateral and contralateral paws over time using two-way ANOVA. Results of Bonferroni post hoc correction: ${ }^{*} p<0.05$; ${ }^{* *} p<0.01$.
}

low baseline density of Merkel cells and to uncertainty about the precise border between sural and tibial territories. In the nearby hairy skin innervated by the spared sural nerve, using TrkC $C^{\text {tdtomato }}$ mice, we observed no changes in the percentage of hair follicles associated with Merkel cells $28 \mathrm{~d}$ after injury (Fig. $2 \mathrm{H}-\mathrm{J}, \mathrm{L}$ ), but by $56 \mathrm{~d}$ there was a slight reduction in this parameter (Fig. $2 L$ ) and in the mean number of Merkel cells per hair follicle (Fig. 2G), compared with baseline. Yet, these levels were not significantly different from those measured on the contralateral side. There was no change in the percentage of Merkel cell clusters with closely apposed $\mathrm{TrkC}^{\text {tdtomato }}$-positive endings (Fig. $2 M$ ) over time or between ipsilateral and contralateral paws.

To determine whether a similar pattern of Merkel cell anatomy with and without nerve injury can be seen in female mice, we compared WT males and females at day 28 after SNI. As in males, we observed Merkel cell loss in the female ipsilateral glabrous hind paw compared with the contralateral side. No 

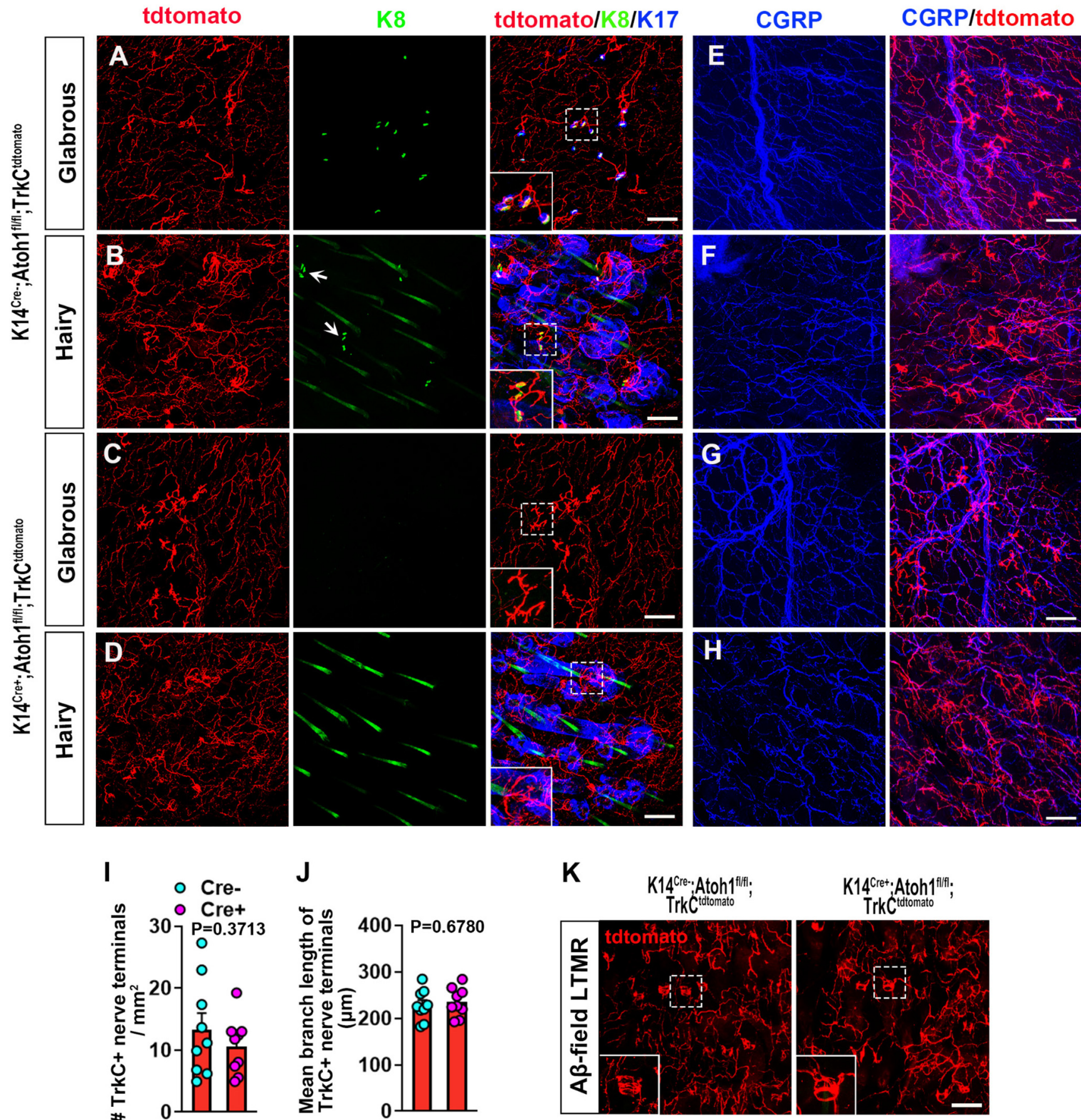

Figure 4. Expression of SAI LTMR endings and other nerve endings in the glabrous and hairy skin of male Merkel cell-deficient and control mice. A-D, Whole-mount immunostaining for tdTomato (red), K8 (green), and K17 (blue) in the glabrous $(\boldsymbol{A})$ and hairy $(\boldsymbol{B})$ skin from control Cre-negative Atoh $7^{\text {fl/ff; }} ; T_{\text {TkC }}^{\text {tdtomato }}$ mice, and the glabrous $(\boldsymbol{C})$ and hairy $(\boldsymbol{D})$ skin from $K 14^{\text {(re }+}$; Atoh ${ }^{f / f i f} ;$ Trk $C^{\text {tdtomato }}$ mice. Insets, Expanded view of Trk ${ }^{\text {tdtomato+ }}$ nerve endings. Long structures in $\mathrm{K} 8$ staining $(\boldsymbol{B}, \boldsymbol{D})$ are autofluorescent or crossreacting hair shafts. Compact structures (arrows in $\boldsymbol{B}$ ) are Merkel cells. Scale bar, $100 \mu \mathrm{m}$. $\boldsymbol{E}-\boldsymbol{H}$, Whole-mount staining for (GRP (blue) and tdTomato (red) in the glabrous $(\boldsymbol{E})$ and hairy $(\boldsymbol{F})$ skin of control mice, and the glabrous $(\boldsymbol{G})$ and hairy

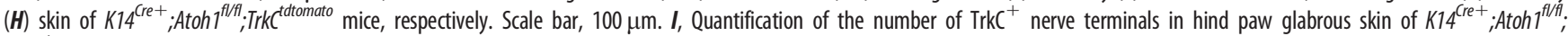
$\operatorname{TrkC}^{\text {tdomato }}(n=9)$ and control $(n=9)$ mice. Data are mean \pm SEM. Unpaired two-tailed Student's $t$ test. J, Quantification of the total branch length per TrkC ${ }^{+}$nerve terminal complex in gla-

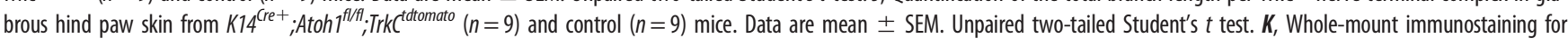
tdTomato in hairy skin of control (left) and $K 14^{\text {Cre+ }} ;$;Atoh $7^{\text {fl/ff }}$; TrkC ${ }^{\text {dtomato }}$ (right) mice. Insets, Amplified view of TrkC ${ }^{\text {tdtomato+ }}$ circumferential nerve endings, which are presumably field LTMRs. Scale bar, $100 \mu \mathrm{m}$.

significant difference was seen between males and females in either paw, although there was a slight trend toward lower Merkel cell density in females, compared with males, in the uninjured glabrous hind paw proximal to foot pads (Fig. $3 A$ ). In the hairy sural territory, there was a small but significant reduction in mean number of Merkel cells per hair follicle in the ipsilateral paw, compared with the contralateral paw, when assessed across all animals tested, but this difference was not significant individually within either males or females (Fig. $3 B$ ). There was no difference in either sex between ipsilateral and contralateral paws in the percentage of hair follicles associated with Merkel cells and no sex difference in this parameter (Fig. 3C). To further assay for 

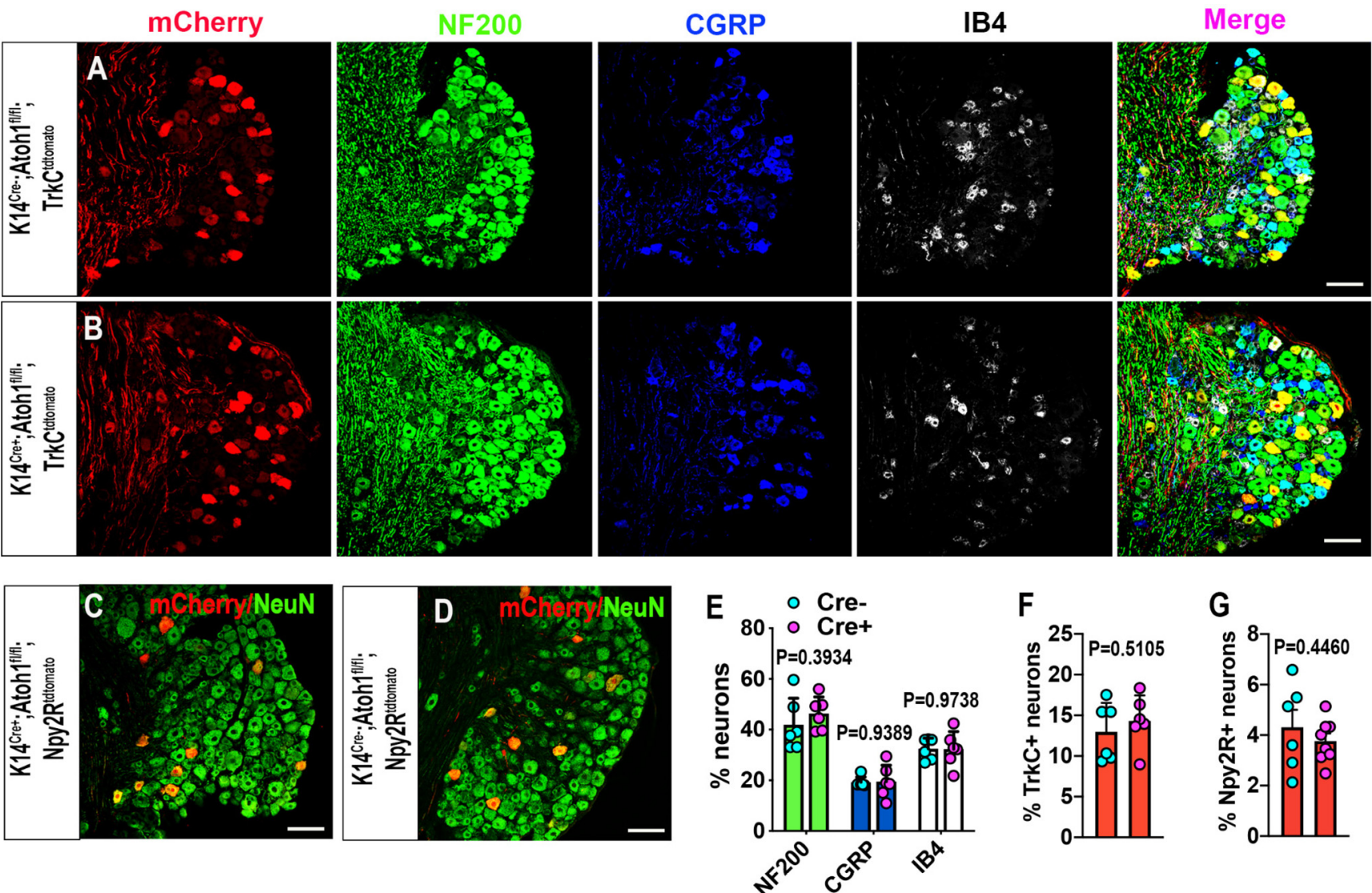

Figure 5. Distribution of TrkC ${ }^{+}$neurons and other neuronal subtypes in lumbar DRGs of male Merkel cell-deficient and control mice. $\boldsymbol{A}, \boldsymbol{B}$, Immunostaining for tdTomato (red), NF200

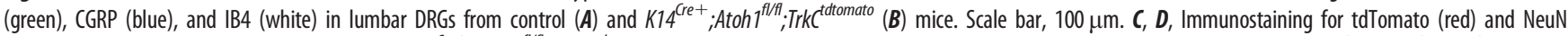

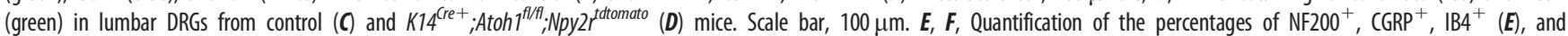

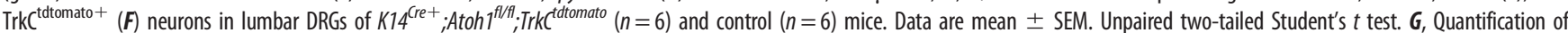
the percentage of Npy2r ${ }^{\text {tdtomato }+}$ neurons in lumbar DRGs of $K 14^{\text {(re+ }} ; A \operatorname{Atoh} 7^{\text {ft/f } ;} ; N p y 22^{\text {tdtomato }}(n=6)$ and control $(n=8)$ mice. Data are mean \pm SEM. Unpaired two-tailed Student's $t$ test.

sex differences in Merkel cell baseline number/density and/or survival rate at longer time after injury, we made an additional comparison of the ipsilateral hind paw in naive versus SNI day 56 male and female mice. Naive and injured mice used in this experiment also were age-matched to eliminate the potential contribution of age-dependent Merkel cell loss (Wright et al., 2017). In the glabrous territory, we observed a slightly lower Merkel cell density in naive females compared with naive males that just reached significance. A significant loss of Merkel cells was observed in both sexes at $56 \mathrm{~d}$ after injury (Fig. 3D). In the hairy sural area, there was no difference in either Merkel cell number per hair follicle or percentage of follicles with Merkel cells between naive and day 56 in either sex, and no sex difference was seen in either treatment group (Fig. $3 E, F$ ). In summary, male and female mice exhibited similar Merkel cell densities in hind paw skin and a similar loss of Merkel cells in denervated glabrous skin. By comparison, Merkel cell loss was minimal in nondenervated hairy sural areas in both sexes.

\section{Deletion of Merkel cells does not affect prevalence or terminal morphology of A $\beta$ SAI LTMRs or other major sensory neuron subtypes}

Previous studies have revealed that Merkel cells can be developmentally eliminated in mice through conditional KO of the transcription factor Atoh1 in precursor cells in the basal epidermis using either $\mathrm{HoxB1} 1^{\mathrm{Cre}}$ or $\mathrm{K} 14^{\mathrm{Cre}}$ driver lines (Maricich et al., 2009, 2012; Maksimovic et al., 2014; Reed-Geaghan et al., 2016;
Feng et al., 2018). We therefore examined male $\mathrm{K}^{\mathrm{Cre+}}{ }^{\mathrm{C}}$;Atoh ${ }^{f l f l}$ and Cre-negative control mice. As expected, the Cre-positive mice exhibited an absence of Merkel cells from hairy and glabrous skin of the hind paw. Prior studies have reported changes in the physiological properties and gene expression patterns of A $\beta$ SAI LTMRs following Merkel cell KO or perturbation (Maricich et al., 2009; Maksimovic et al., 2014; Reed-Geaghan et al., 2016; Feng et al., 2018). In multiple studies, touch domes and touch dome-innervating afferents were shown to persist in the KO mice. However, whereas in one study Merkel cell loss was found to result in expanded branching of the touch dome-associated afferent terminals (Maricich et al., 2009), this was not the case in another study (Maksimovic et al., 2014). We further explored this issue, using $\mathrm{K} 14^{\mathrm{Cre}+} ;$; toh $1^{\text {fl/fl }}$; Trk $C^{\text {tdtomato }}$ mice. In the glabrous skin of control Cre-negative Atoh $1^{\text {flflf }} ; \operatorname{TrkC}^{\text {tdtomato }}$ mice, we observed tdTomato-labeled terminal complexes with a distinct branched morphology. Of these structures, $44.0 \%$ were in close contact with Merkel cells (Fig. $4 A, B$ ), making them likely to be the terminals of $\mathrm{A} \beta$ SAI-LTMRs. Neither the density of these terminal complexes nor the total branch length per complex, measured from $2 \mathrm{D}$ projections of confocal $z$-stack images, was altered in the $K 14^{\mathrm{Cre}+} ;$ Atoh $1^{\text {flffl }}$; Trk $C^{\text {tdtomato }}$ mice (Fig. $4 A-D, I, J)$, suggesting that the terminal anatomy of glabrous skin SAI neurons is not overtly modified by the absence of Merkel cells. In adjacent hairy skin, TrkC ${ }^{\text {tdtomato }}$-positive Merkel cell-associated terminals and circumferential LTMR endings (likely $\mathrm{A} \beta$ Field-LTMRs) were in close proximity, and the 

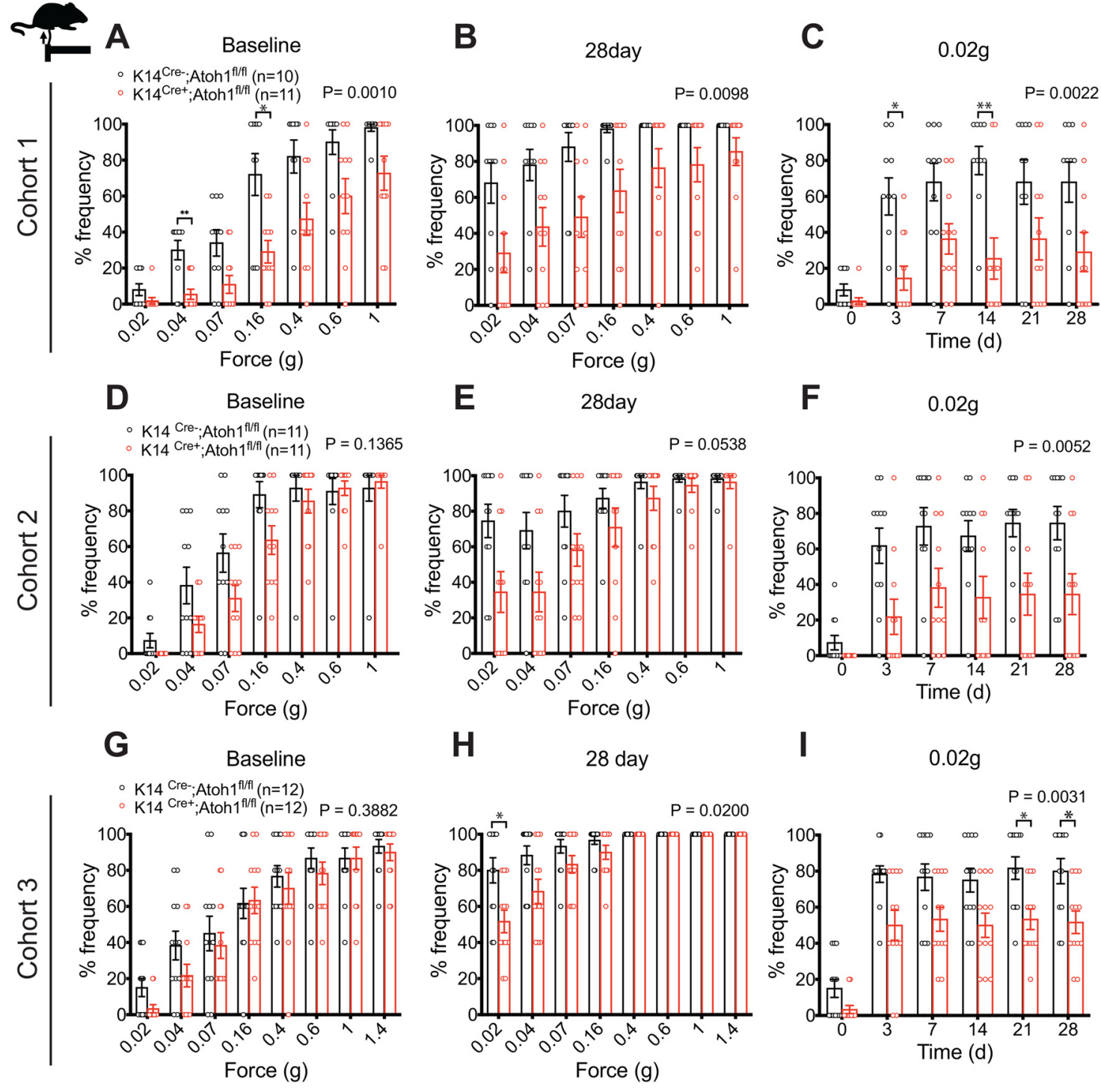

Baseline

K

28DAY
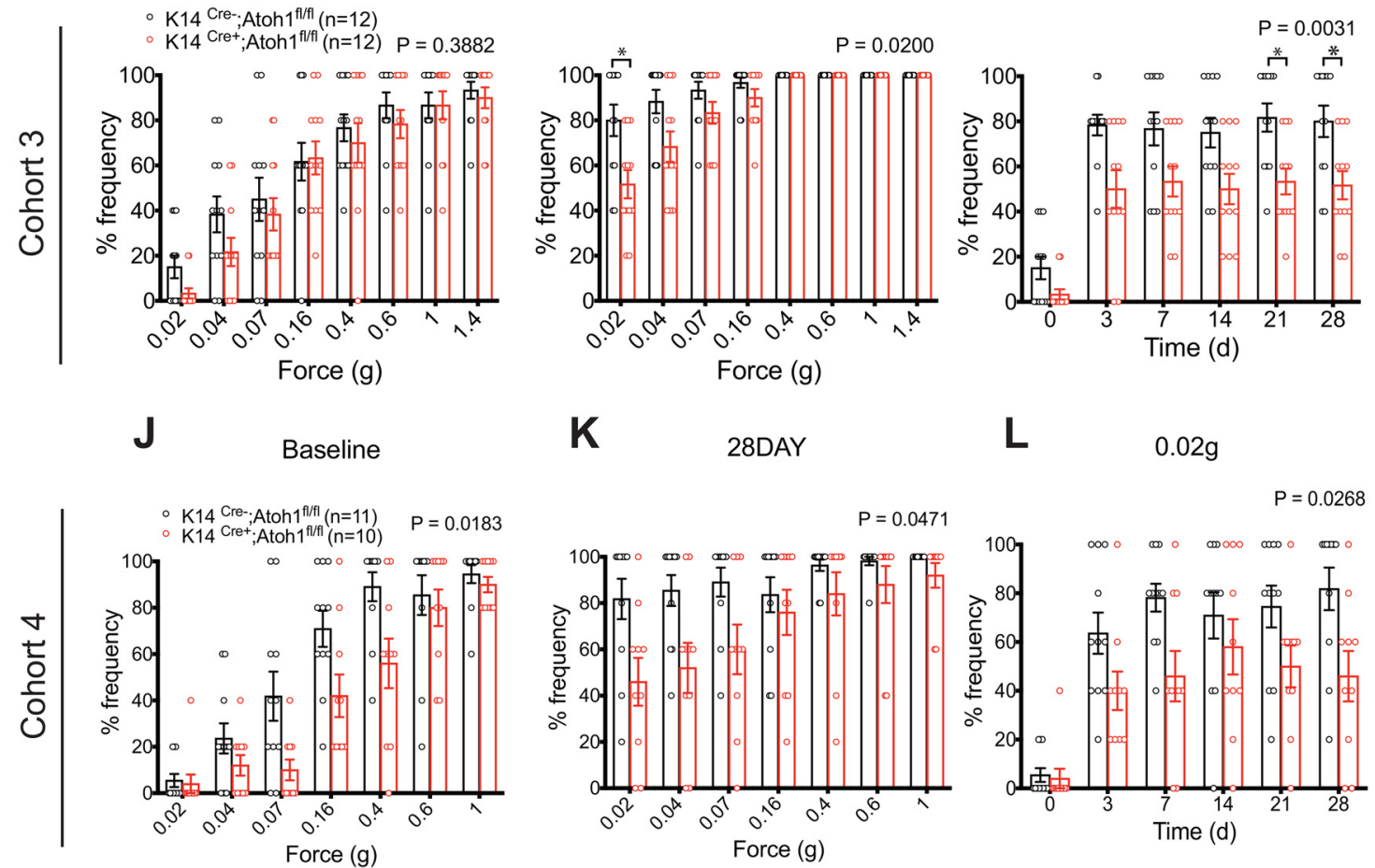

Figure 6. Nerve injury induced punctate mechanical allodynia in Merkel cell-deficient male mice in the SNI model. $A-L$, Punctate mechanical sensitivity measured across forces in the ipsilat-

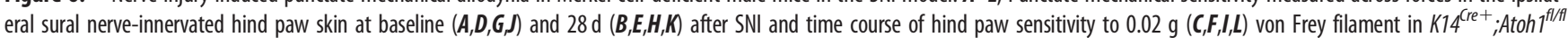
and Cre-negative Atoh $7^{t / f / f}$ control male mice. A-C, Cohort 1. D-F, Cohort 2. G-I, Cohort 3. J-L, Cohort 4. Data are mean \pm SEM. Two-way ANOVA with $p$ value from overall comparison between genotypes over time or force shown at top and number of mice in parentheses. Results of Bonferroni post hoc correction: ${ }^{*} p<0.05$; ${ }^{* *} p<0.01$; Cre-positive versus Cre-negative.

presumptive SAI terminals lacked the distinct morphology noted in glabrous skin, precluding a quantitative comparison between genotypes in this region. There were also no notable differences between $\mathrm{K}_{14}{ }^{\mathrm{Cre}{ }^{+}}$;Atoh $1^{\text {fl/fl }}$; TrkC $\mathrm{C}^{\text {tdtomato }}$ mice and Cre-negative controls in the appearance of CGRP-positive fibers (Fig. 4. E-H) or circumferential $\mathrm{A} \beta$ Field-LTMRs endings in hairy skin
(Fig. 4K). Together, these findings suggest that Merkel cell $\mathrm{KO}$ does not obviously alter the morphology of paw skin peripheral nerve terminals among the subtypes and locations examined.

Given the effects of Merkel cell deletion on DRG gene and protein expression reported by others, we sought to clarify whether deletion of Merkel cells would impact the prevalence of 
different neuronal subtypes in lumbar DRGs. We performed immunostaining for neuronal markers NF200 (myelinated neurons), CGRP (peptidergic nociceptors), and IB4 (nonpeptidergic nociceptors), and for tdTomato in lumbar DRGs of $\mathrm{K}_{14}^{\mathrm{Cre+}}$;Atoh $1^{f l / f l}$; Trk $C^{\text {tdtomato }}$ mice. As previously reported (Bai et al., 2015; Reed-Geaghan et al., 2016), TrkC tdtomato DRGs showed tdTomato labeling mainly in NF200 large-sized DRG neurons and in some $\mathrm{NF} 00^{+} \mathrm{CGRP}^{+}$neurons, but there was no significant difference in tdTomato-labeled neuron prevalence between genotypes. $\mathrm{K} 4^{\mathrm{Cre+}}$; Atoh $1^{f l / f l}$; Trk $C^{\text {tdtomato }}$ mice also exhibited similar prevalence of $\mathrm{NF}_{200}{ }^{+}, \mathrm{CGRP}^{+}$, and $\mathrm{IB}^{+}$neurons to control mice (Fig. 5A,B,E,F). Finally, we crossed K14 ${ }^{\text {Cre }}$;Atoh $1^{\text {flfl }}$ mice with $N p y 2 r^{\text {tdtomato }}$ mice, to label a population of neurons that includes A $\beta$ RA LTMRs (Li et al., 2011). Again, no differences were noted in the prevalence of these neurons in the DRGs of Merkel cell KO mice versus controls (Fig. 5C,D,G). With the caveat that only a subset of labeled neurons in TrkC $C^{\text {tdtomato }}$ mice are $\mathrm{A} \beta$ SAI LTMRs, the findings described above collectively suggest that neither the abundance nor the terminal morphology of $A \beta$ SAI LTMRs was substantially altered in the absence of Merkel cells, and that other major neuronal subtypes are also present at normal prevalence.

\section{Deletion of Merkel cells reduces} mechanical hypersensitivity after sural sparing nerve injury in male mice

To explore the functional importance of Merkel cells in neuropathic pain, we evaluated punctate and dynamic painrelated behaviors in Merkel cell $\mathrm{KO}$ mice before and after SNI surgery. We examined four independent mouse cohorts over a period of 3 years. Cohorts 1, 2, and 4 were assayed by one investigator, while Cohort 3 was assayed by a second investigator. Punctate mechanical sensitivity was assessed in the glabrous skin territory innervated by the spared sural nerve using von Frey filaments. In the first and fourth cohorts tested, we observed a reduction in baseline punctate mechanosensitivity in $\mathrm{K}^{\mathrm{Cre+}}{ }^{\mathrm{C}}$; Atoh $\mathrm{f}^{\mathrm{fl} / \mathrm{ll}}$ mice, compared with Cre-negative controls (Fig. 6A,J). However, no significant reduction was observed in Cohort 2 (Fig. 6D) or Cohort 3 (Fig. 6G). In all four cohorts, SNI surgery produced a leftward shift in the force-response profile in both genotypes. However, at $28 \mathrm{~d}$ after surgery, we observed reduced mechanical hypersensitivity in $\mathrm{K} 4^{\mathrm{Cre}+}$;Atoh1 $1^{\mathrm{fl} f \mathrm{ll}}$ mice, compared with controls, after SNI

E

G

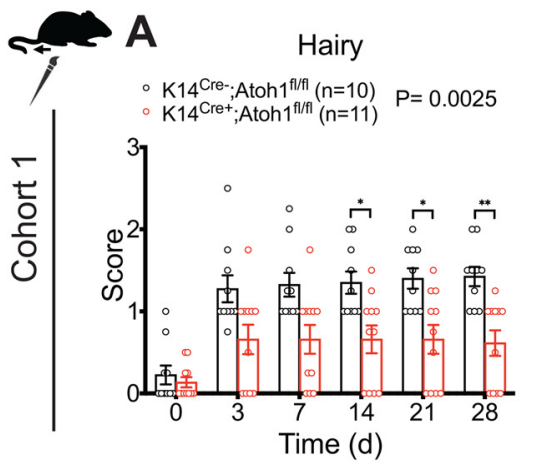

B Glabrous
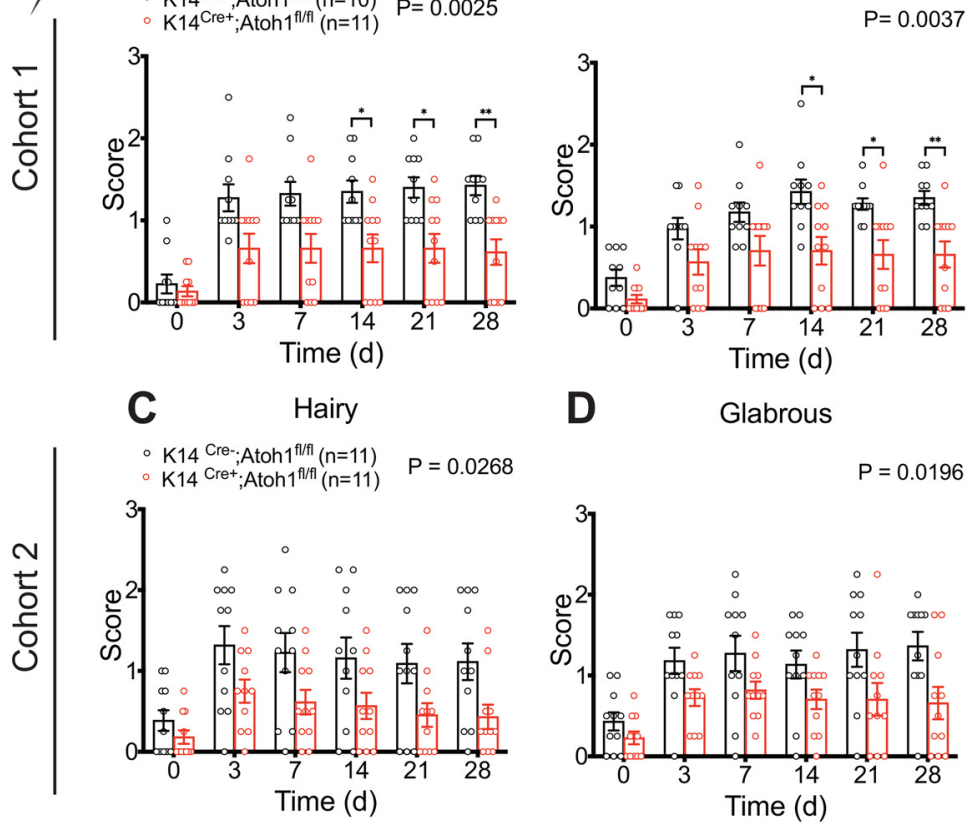

D Glabrous

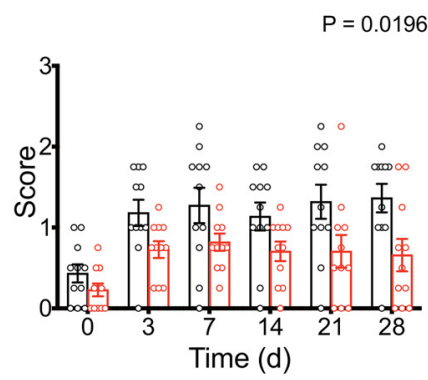

Hairy

$\mathbf{F}$

Glabrous

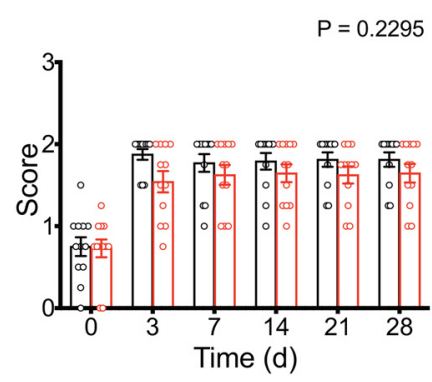

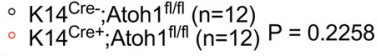

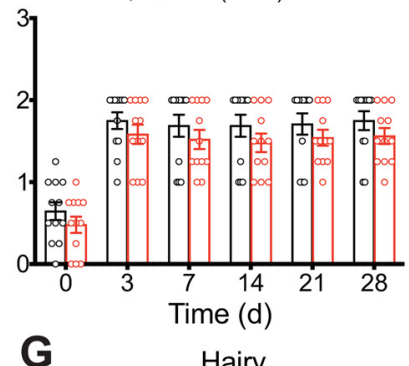

Hairy

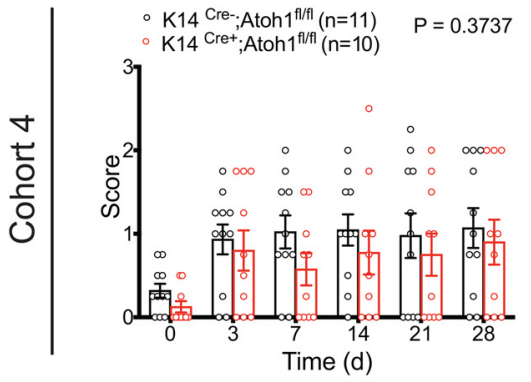

Figure 7. Nerve injury induced dynamic mechanical allodynia in Merkel cell-deficient male mice in the SNI model. $A-G$ Time course of brush-evoked dynamic mechanical sensitivity, after $S N I$, in the ipsilateral sural nerve-innervated glabrous $(\boldsymbol{B}, \boldsymbol{D}$, F) and neighboring hairy $(A, C, E, G)$ skin of $K 14^{(\text {re+ }} ; A t o h t^{f / f t}$ and control male mice. $A, B$, Cohort 1. C, D, Cohort 2. E, F, Cohort 3. $\mathbf{G}$, Cohort 4. Data are mean \pm SEM. Two-way ANOVA with $p$ value from overall comparison between genotypes over time or force shown at top and number of mice in parentheses. Results of Bonferroni post hoc correction: ${ }^{*} p<0.05$; ${ }^{* *} p<0.01$; Cre-positive versus Cre-negative. Extended Data Figures 7-1 and 7-2 support Figure 7.

(Fig. $6 B, E, H, K$ ) that reached significance in an overall analysis across forces in three of the four cohorts. Indeed, when we examined responses to the lowest force $(0.02 \mathrm{~g})$ over time after injury, K14 ${ }^{\text {Cre+ }}$;Atoh1 $1^{\text {fl/fl }}$ mice showed significantly less sensitization than controls in all four cohorts (Fig. $6 C, F, I, L$ ). These data are consistent with a reduction in punctate allodynia in these mice. In Cohorts 1 and 2, K14 ${ }^{\mathrm{Cre}+}$; Atoh $\mathrm{f}^{\mathrm{fl} / \mathrm{ll}}$ mice also showed a reduction in dynamic allodynia, assayed by brush stimulation of the 
Cohort 1

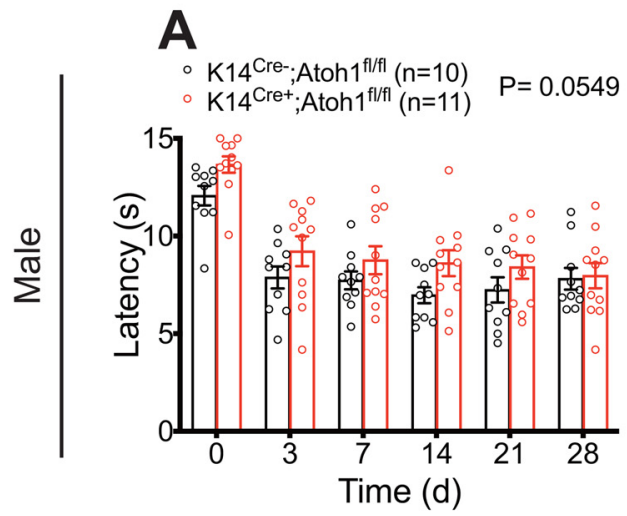

D

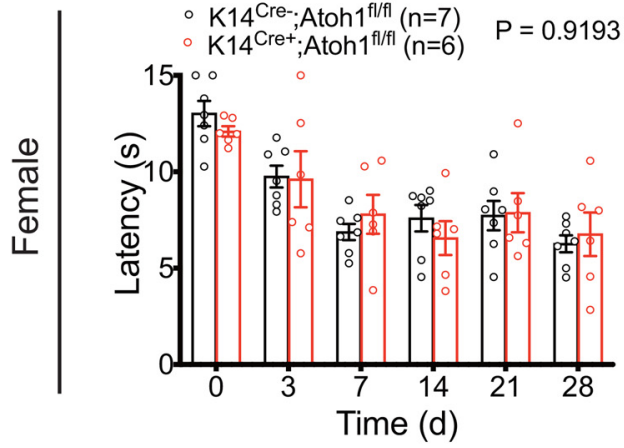

Cohort 2
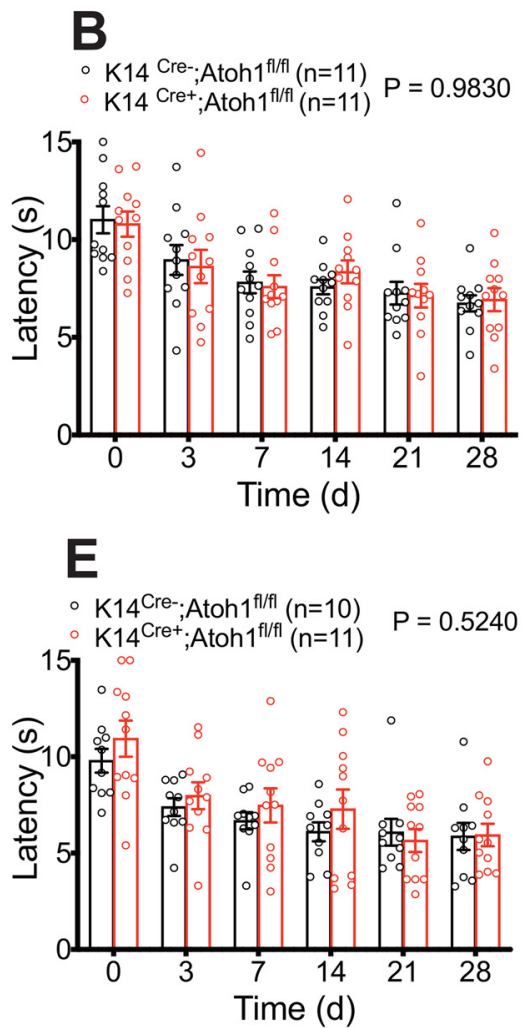

Cohort 3
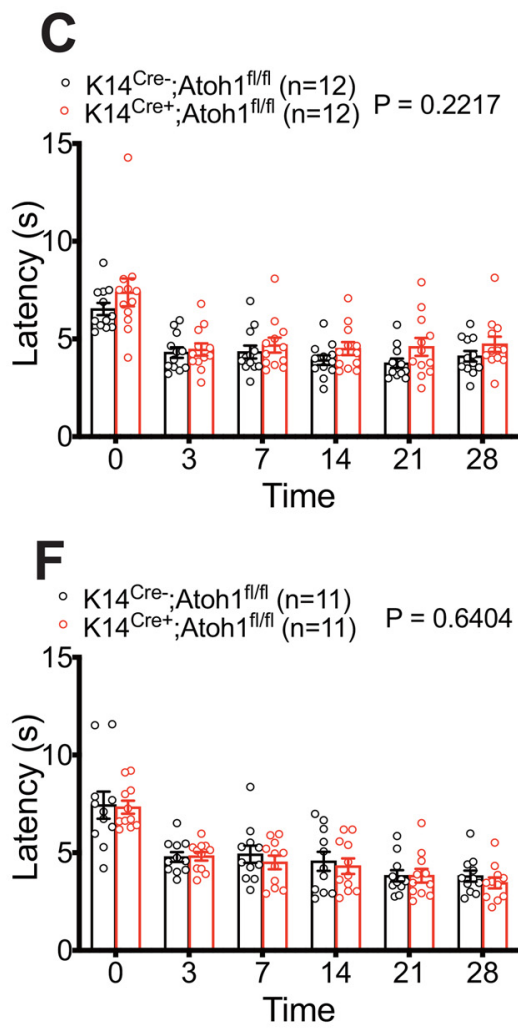

Figure 8. Nerve injury induced thermal hyperalgesia in Merkel cell-deficient male and female mice in the SNI model. $\boldsymbol{A}-\boldsymbol{C}$, Time course of thermal sensitivity after SNI on ipsi-

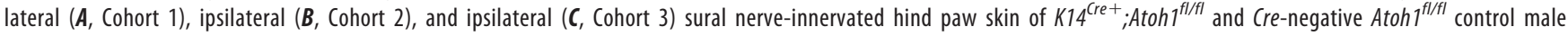
mice. $\boldsymbol{D}-\boldsymbol{F}$, Time course of thermal sensitivity after SNI on ipsilateral ( $\boldsymbol{D}$, Cohort 1), ipsilateral (E, Cohort 2), and ipsilateral $(\boldsymbol{F}$, Cohort 3) sural nerve-innervated hind paw skin in $\mathrm{K}^{\mathrm{Cre}+}{ }^{\mathrm{C}} ; \mathrm{Atoh} 7^{\mathrm{fl} / \mathrm{fl}}$ and Cre-negative Atoh $7^{\mathrm{fl} / \mathrm{fl}}$ control female mice. Data are mean $\pm \mathrm{SEM}$. Two-way ANOVA with $p$ value from overall comparison between genotypes over time shown at top and number of mice in parentheses.

hairy skin innervated by the spared sural nerve, but no such difference was observed in Cohorts 3 or 4 (Fig. $7 A, C, E, G$ ). In the glabrous skin, $\mathrm{K}_{14}{ }^{\mathrm{Cre}+}$;Atoh $1^{\text {flfl }}$ mice showed a reduction in dynamic allodynia in Cohorts 1 and 2 but not in Cohort 3 (Fig. $7 B, D, F)$. Dynamic allodynia was not assayed in the glabrous skin of Cohort 4. In addition, we merged the data for the cohorts assayed by the same investigator (Extended Data Fig. 7-1A-E) and the data for all four cohorts (Extended Data Fig. 7-1F-J). Both of these aggregate analyses revealed not only a significant reduction in punctate and dynamic mechanosensitivity after SNI, but also a decrease in baseline punctate mechanosensitivity in $\mathrm{K}_{14}{ }^{\mathrm{Cre}+}$;Atoh $\mathrm{f}^{f l f l}$ mice. To exclude the possible contribution of genetic background to our $\mathrm{KO}$ findings, we crossed $\mathrm{K} 14^{\mathrm{Cre}+}$; Atoh ${ }^{f l f l}$ mice one generation against WT C57BL/6J mice to omit one of the Atoh $\mathrm{f}^{f l}$ alleles, and then intercrossed the resulting animals to produce $\mathrm{K} 4^{\mathrm{Cre}+} ;$ Atoh $1^{+/+}$mice and Cre-negative Atoh $1^{+/+}$controls. Examination of both punctate and dynamic mechanosensitivity in these mice before and after SNI revealed no differences between genotypes (Extended Data Fig. 7-2A-E), arguing against genetic background as a cause of the findings in the Merkel cell $\mathrm{KO}$ mice. In addition, the fact that Cohort 4 of the Merkel cell-deficient mice was generated and assayed after the assay of $\mathrm{K}_{14}{ }^{\mathrm{Cre}+}$; Atoh $1^{+/+}$mice indicates that genetic drift in our colony could not explain the difference in punctate allodynia phenotype between these two lines. In contrast to the mechanosensory phenotype, we observed no significant differences in thermal hyperalgesia between male $\mathrm{K} 4^{\mathrm{Cre}+}$;A toh $1^{\mathrm{fl} / \mathrm{fl}}$ mice and Atoh $1^{f l f l}$ controls after SNI in any of the three cohorts tested (Fig. 8A-C). Together, these findings provide evidence for a consistent deficit in nerve injury-induced behavioral hypersensitivity to low-intensity punctate mechanical stimulation in Merkel cell-deficient mice, with additional possible but inconsistent defects in baseline mechanosensitivity and dynamic allodynia-like behavior.

\section{Influence of Merkel cell absence on mechanical allodynia is sex-dependent}

Sex differences have been reported in many chronic pain conditions, including neuropathic pain (Smith et al., 2006; Torrance et al., 2006; Bouhassira et al., 2008; Hurley and Adams, 2008; Fillingim et al., 2009; Sorge et al., 2015; Taves et al., 2016; Mapplebeck et al., 2018). Therefore, we also examined pain behaviors in Merkel cell-deficient female mice. Because of variable availability of experimental animals of a given sex, assays on male versus female cohorts were asynchronous but interdigitated. As with male mice, Cohorts 1, 2, and 4 were assayed by one investigator and Cohort 3 by another investigator. In all four cohorts, $\mathrm{K} 4^{\mathrm{Cre}+}$;Atoh $\mathrm{P}^{\mathrm{fl} / \mathrm{fl}}$ female mice displayed no significant difference in punctate allodynia, compared with control mice (Fig. 9), although a trend toward reduction was observed in Cohort 1 (Fig. $9 A-C)$. Similarly, we observed no significant difference in dynamic allodynia in hairy or glabrous skin between genotypes (Fig. 10). Furthermore, no significant difference was observed when data were merged for the three cohorts $(1,2$, and 4$)$ assayed by the same investigator (Extended Data Fig. 10-1A-E) or for all four 

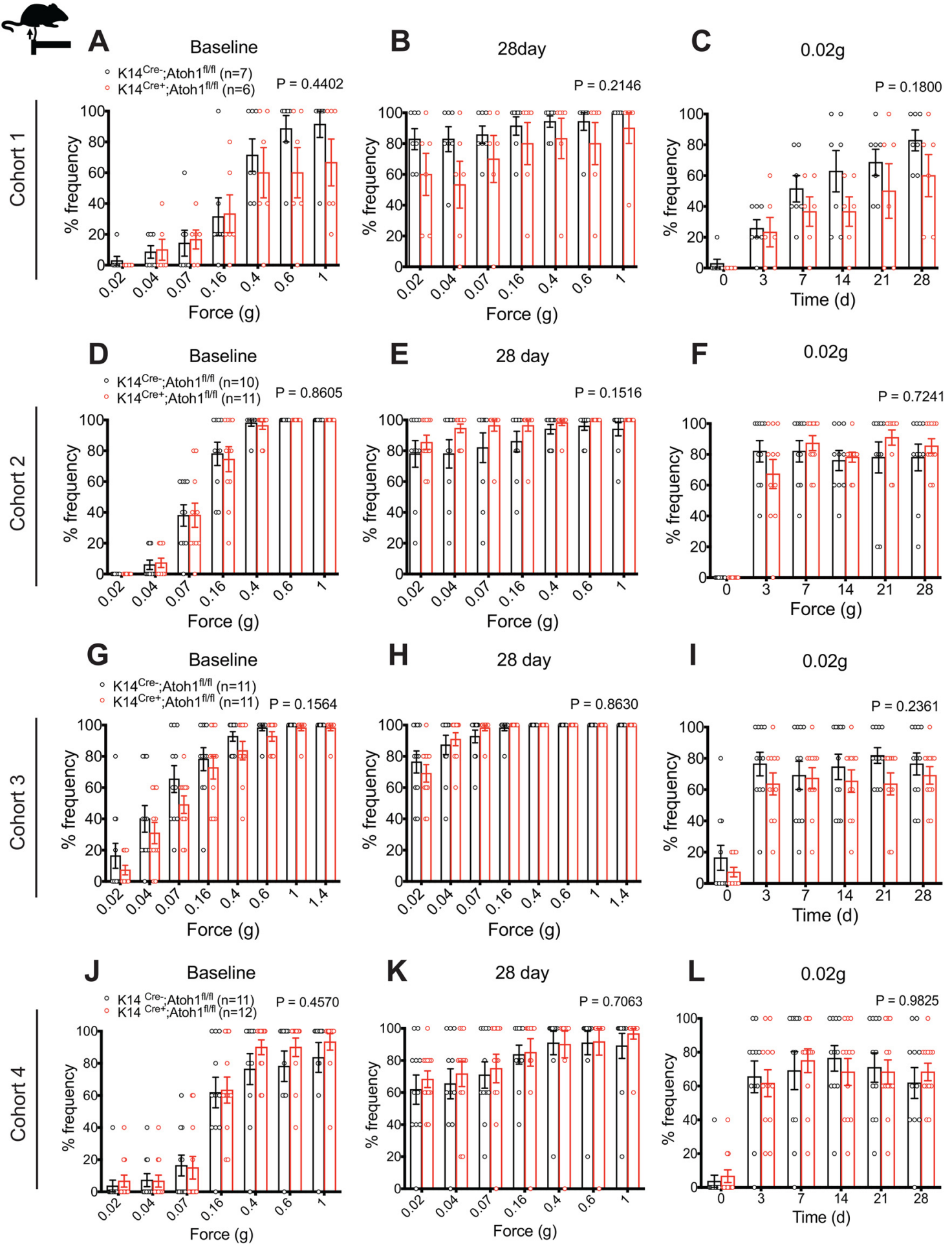

Figure 9. Nerve injury induced punctate mechanical allodynia in Merkel cell-deficient female mice in the SNI model. $A-L$, Punctate mechanical sensitivity measured across forces in the ipsilateral sural nerve-innervated hind paw skin at baseline $(\boldsymbol{A}, \boldsymbol{D}, \boldsymbol{G}, \boldsymbol{J})$ and $28 \mathrm{~d}(\boldsymbol{B}, \boldsymbol{E}, \boldsymbol{H}, \boldsymbol{K})$ after $S \mathrm{NI}$ and time course of hind paw sensitivity to $0.02 \mathrm{~g}(\boldsymbol{C}, \boldsymbol{F}, \boldsymbol{I}, \boldsymbol{L})$ von Frey filaments in $\mathrm{K}^{\mathrm{C} 4^{\mathrm{Cre}+}}$;Atoh $7^{\mathrm{fl} / \mathrm{fl}}$ and Cre-negative Atoh $7^{\mathrm{fl} / f l}$ control female mice. A-C, Cohort 1. D-F, Cohort 2. G-I, Cohort 3. J-L, Cohort 4. Data are mean \pm SEM. Twoway ANOVA with $p$ value from overall comparison between genotypes over time or force shown at top and number of mice in parentheses.

cohorts (Extended Data Fig. 10-1F-J). We also observed no significant differences in thermal hyperalgesia between $\mathrm{K}_{14}{ }^{\mathrm{Cre}+} ;$ Atoh $1^{f l / f l}$ and control females (Fig. $8 D-F$ ). These results suggest that the contribution of Merkel cells to nerve injury induced mechanical allodynia is confined to male mice.
Merkel cell density and mechanical sensitivity in a tibial sparing nerve injury model

A previous study in rats showed that, in an SNI model variant where the tibial nerve instead of the sural nerve is spared (SNIt), strong mechanical hypersensitivity was observed in the middle of the paw, and this was accompanied by increased Merkel cell 

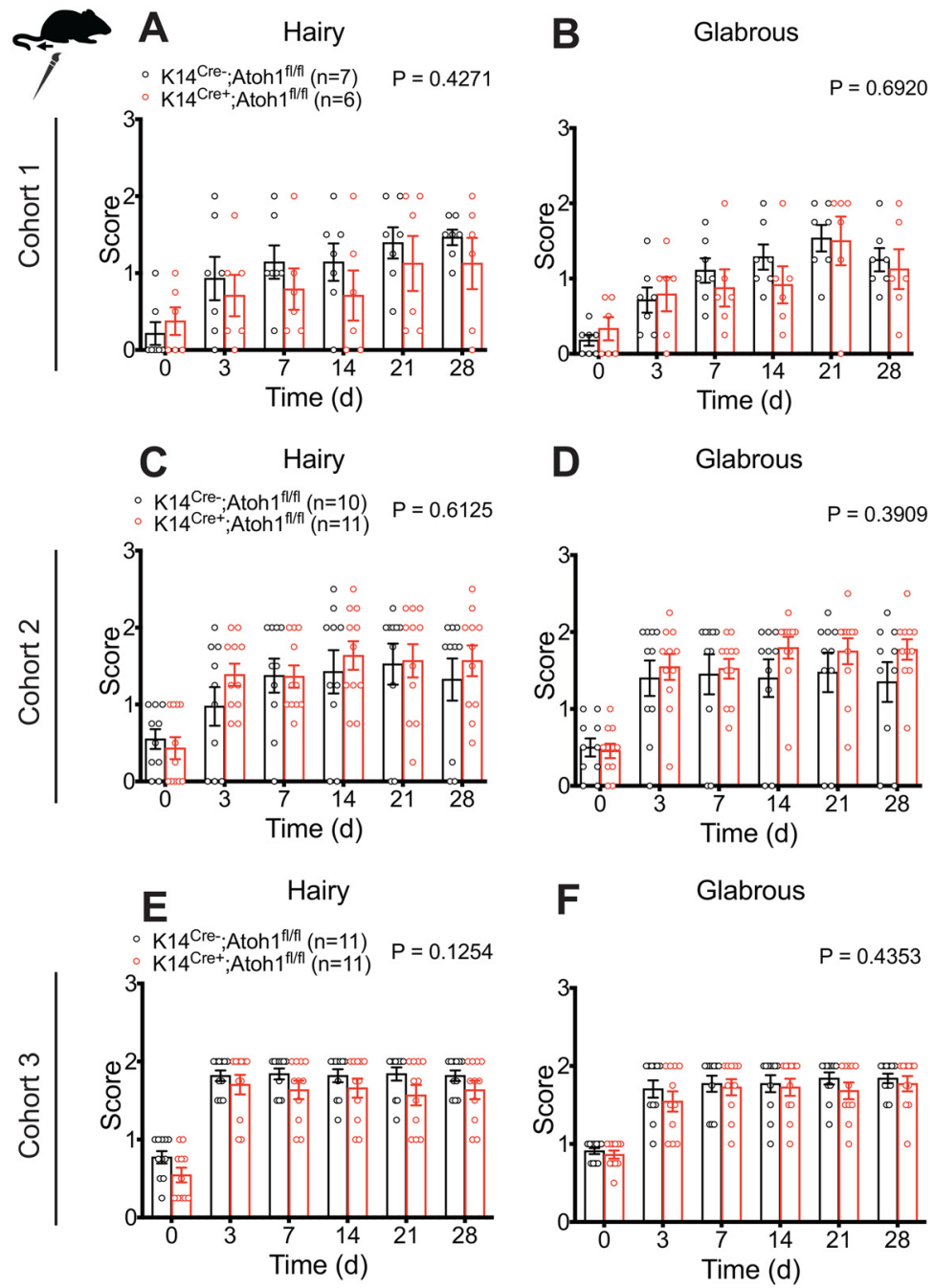

$\mathbf{F}$

Glabrous
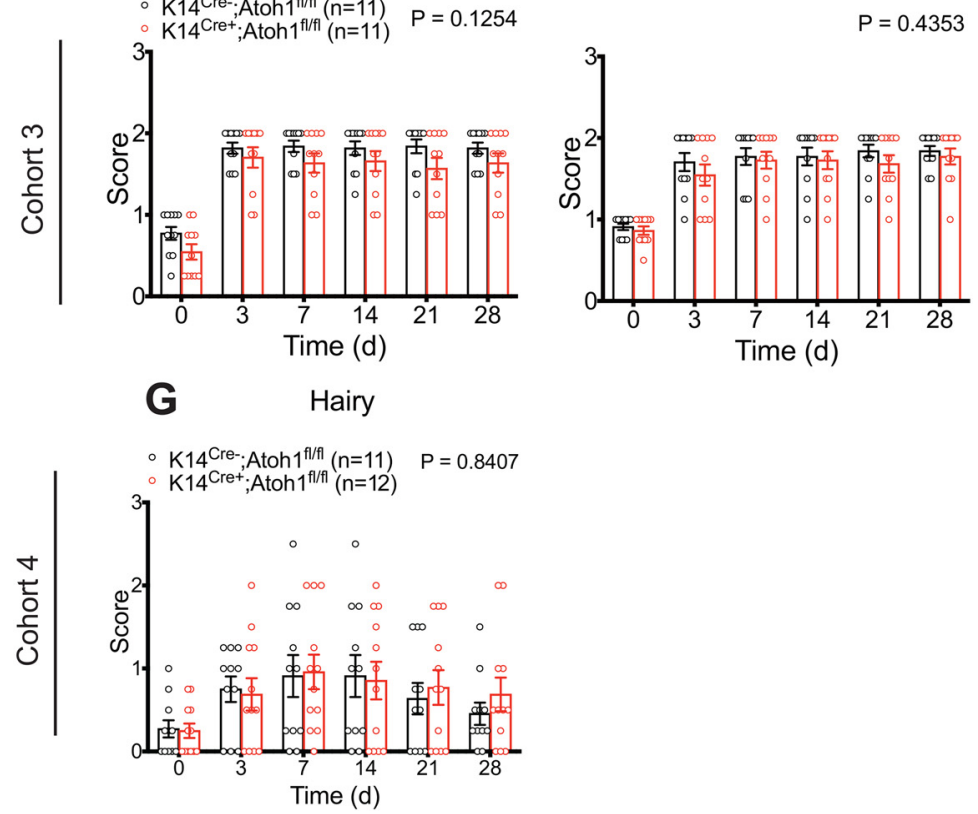

Figure 10. Nerve injury induced dynamic mechanical allodynia in Merkel cell-deficient female mice in the SNI model. $A-G$, Time course of brush-evoked dynamic mechanical sensitivity, after $S N I$, in the ipsilateral sural nerve-innervated glabrous $(\boldsymbol{B}, \boldsymbol{D}, \boldsymbol{F})$ and neighboring hairy $(\boldsymbol{A}, \boldsymbol{C}, \boldsymbol{E}, \boldsymbol{G})$ skin of $K 14^{\mathrm{Cre}+} ; A$ toh $7^{f / f t}$ and control female mice. $\boldsymbol{A}, \boldsymbol{B}$, Cohort 1. $\boldsymbol{C}, \boldsymbol{D}$, Cohort 2. $E, F$, Cohort 3. $G$, Cohort 4. Data are mean \pm SEM. Two-way ANOVA with $p$ value from overall comparison between genotypes over time or force shown at top and number of mice in parentheses. Extended Data Figure 10-1 supports Figure 10.

density in the first foot pad, which is innervated by the spared tibial nerve (Ko et al., 2016). However, other investigators have reported variable levels of behavioral hypersensitivity when this model was performed on mice (Shields et al., 2003; Bourquin et al., 2006). To explore this issue further, we performed the same set of behavioral tests on $\mathrm{K}_{14}{ }^{\mathrm{Cre}+}$;Atoh $1^{f l / f l}$ mice and Cre-negative controls before and up to $14 \mathrm{~d}$ after SNIt. Punctate mechanical sensitivity was tested in the hairy plantar area between the foot pads (Fig. 11A) using von Frey filaments. In contrast to our findings in the mouse sural-sparing SNI model, and in contrast to the reported robust effect reported in rats, SNIt produced only a slightly leftward shift in the forceresponse profile in both $\mathrm{K}_{14}{ }^{\mathrm{Cre}+}$;Atoh $\mathrm{f}^{\mathrm{fl} / \mathrm{fl}}$ male mice and Cre-negative controls (Fig. $11 B, C)$. The small amount of sensitization observed was most evident in the middle forces (Fig. 11D,E) instead of the weakest forces, where the largest effects were seen in the sural sparing model. No significant difference in punctate mechanosensitivity was seen between $\mathrm{K}_{14}{ }^{\mathrm{Cre}+}$;Atoh $1^{f l / f l}$ male mice and Cre-negative controls over the postsurgical time course (Fig. 11B-E), and no difference between the genotypes was observed in dynamic mechanosensitivity or thermal sensitivity (Fig. 11F,G). Interestingly, in contrast to the rat study, Merkel cell density, assayed in the nondenervated first foot pad, did not increase in mice subjected to SNIt (Fig. 11H,I). These findings, together with the lack of Merkel cell density increase in the spared sural area after SNI, support the idea that, at least in mice, increased Merkel cell abundance is not required for allodynia.

\section{Discussion}

Merkel cells have been studied mostly in hairy skin and foot pads, although Merkel cells that disappear by 6 weeks of age have been reported in glabrous skin outside of foot pads (Nurse and Diamond, 1984; Nurse et al., 1984a,b; Mills et al., 1989; Li et al., 2011; Doucet et al., 2013; Feng et al., 2018). In adult mouse, we observed Merkel cells in hind paw foot pads, dorsolateral paw skin hair follicles, non-foot pad glabrous skin, and a recently described population of hair follicles in plantar hind paw skin (Walcher et al., 2018). These follicles had been suggested to receive predominant innervation from $\mathrm{A} \delta$-LTMRs, plus neurons with circumferential endings (Walcher et al., 2018). Together with Merkel cells in these follicles, we observed closely associated nerve terminals of the TrkC lineage, and speculate that these include $\mathrm{A} \beta$ SAI LTMRs.

Following SNI surgery, we observed a loss of Merkel cells from denervated glabrous skin. Studies in rat and cat touch dome and paw hairy skin revealed long-lasting Merkel cell loss following cutaneous nerve transection (English et al., 1983; Nurse et al., 1984a,b; Mills et al., 1989). In mouse hairy skin, denervation was also shown to produce slow-onset loss of Merkel cells (Xiao et al., 2015). Our data suggest that, in mouse glabrous skin, persistent innervation is also required for Merkel cell maintenance.

Rats undergoing SNIt surgery exhibited increased Merkel cell density in tibial nerve-innervated foot pads (Ko et al., 2016). Increased Merkel cell density has also been observed following 

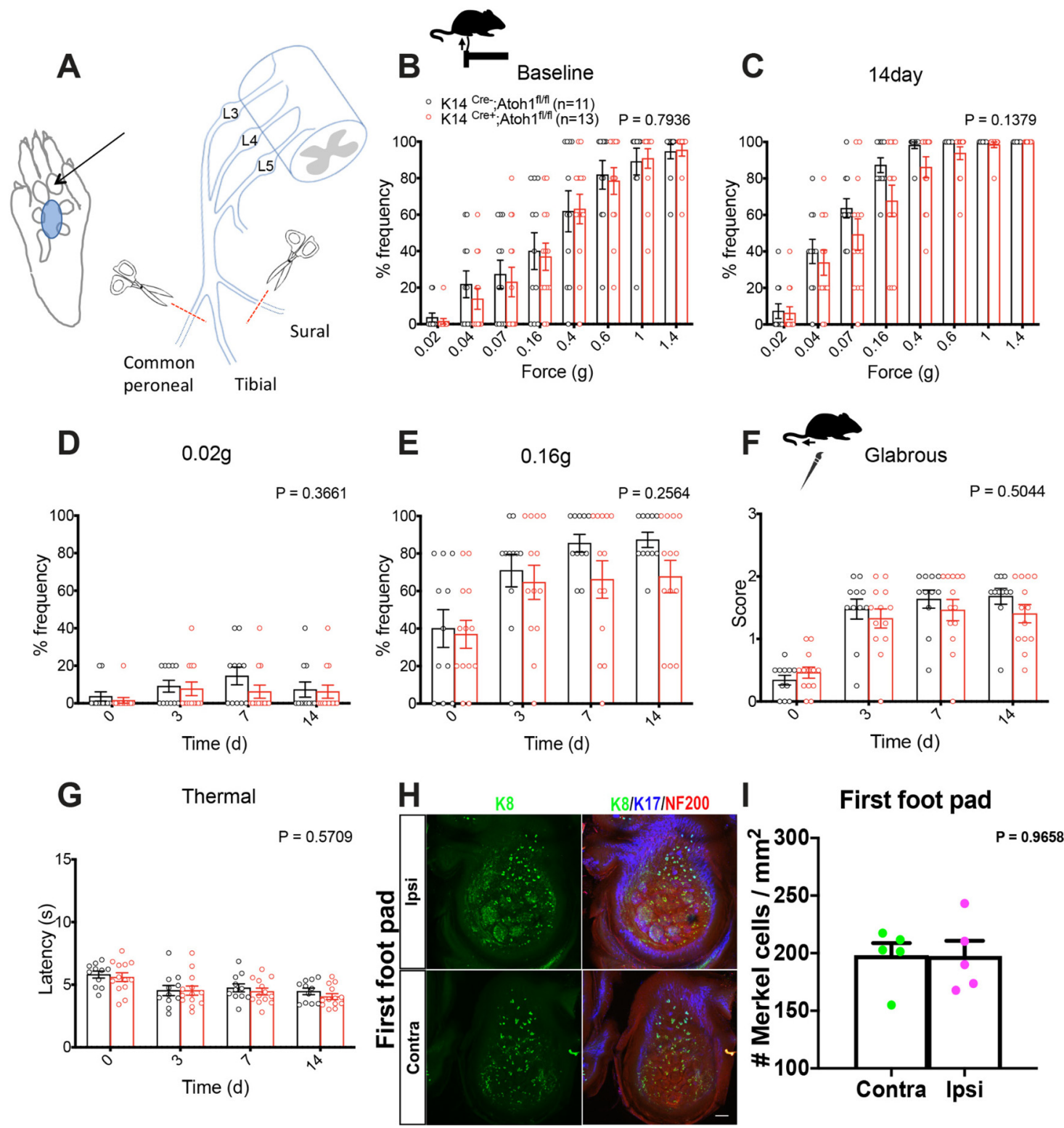

Figure 11. Mechanical sensitivity and Merkel cell density in the spared territory of male mice in the SNIt model. $A$, Right, Schematic diagram of SNIt injury model, showing the three branches of the sciatic nerve (common peroneal, tibial, and sural). Left, Area tested in behavioral assays shown in blue. Arrow indicates first foot pad. $\boldsymbol{B}-\boldsymbol{E}$, Punctate mechanical sensitivity measured across forces in the ipsilateral tibial nerve-innervated hind paw skin at baseline $(\boldsymbol{B})$ and $14 \mathrm{~d}$ after SNIt $(\boldsymbol{C})$ and time course of hind paw sensitivity to $0.02 \mathrm{~g}(\boldsymbol{D})$ and $0.16 \mathrm{~g}(\boldsymbol{E})$ von

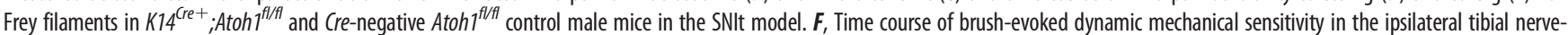
innervated plantar hind paw skin in $\mathrm{K}^{\mathrm{Cre}+}{ }^{\mathrm{r}}$; Atoh $7^{f / f t}$ and Cre-negative control male mice in the SNIt model. G, Time course of thermal sensitivity in the ipsilateral tibial nerve-innervated plan-

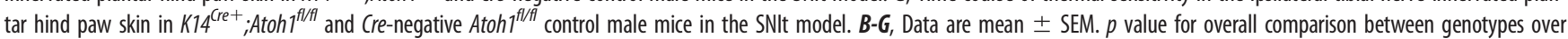
time or force using two-way ANOVA shown at the top and number of mice in parentheses. $\boldsymbol{H}$, Whole-mount immunostaining for K8 (green), K17 (blue), and NF200 (red) in the contralateral and ipsilateral first foot pad at $14 \mathrm{~d}$ after SNIt. Scale bar, $100 \mu \mathrm{m}$. I, Quantification of Merkel cell density in contralateral (green) and ipsilateral (magenta) first foot pad. Data are mean \pm SEM. $p$ value from paired Student's $t$ test shown at the top. $n=5$ mice.

repetitive skin shaving (Wright et al., 2017) and in the painful skin disorder pachyonychia congenita (Pan et al., 2016). In the mouse sural sparing SNI model, we observed no significant difference in Merkel cell density in spared hairy skin $56 \mathrm{~d}$ after injury when comparing ipsilateral versus contralateral paws or when comparing age-matched naive versus SNI mice. In the SNIt model, we also observed no change in Merkel cell density in spared territory foot pads. Thus, in mouse, increased Merkel cell density in spared territories is not an obligate consequence of nerve injury or prerequisite for allodynia.

In humans, myelinated touch-sensitive afferents have been implicated in stroking allodynia (Campbell et al., 1988; Ochs et al., 1989; Koltzenburg et al., 1994). Animal studies have supported the contribution of $\mathrm{A} \beta$ afferents to neuropathic mechanical allodynia (Garrison et al., 2012; Zhu and Henry, 2012; Boada et al., 2015; Xu et al., 2015; Dhandapani et al., 2018). There is some evidence that $\mathrm{A} \delta$ and/or $\mathrm{A} \beta$-RA LTMRs contribute to mechanical allodynia (Xu et al., 2015; Dhandapani et al., 2018). However, assignment of the specific A fiber classes involved in mechanical allodynia is incomplete.

The Merkel cell- $\mathrm{A} \beta$ afferent complex is a well-established mechanosensory structure. Yet, its contributions to pain remain unresolved. Behavioral withdrawal responses to weak innocuous mechanical stimuli were shown to be diminished in $\mathrm{K} 14^{\mathrm{Cre}}$; 
Piezo $2^{f l f l}$ mice, in which cells of epidermal origin, including Merkel cells, lack Piezo2 (Woo et al., 2014). Evidence for participation of Merkel cells in mechanical hypersensitivity following capsaicin injection has come from a study in which Piezo2 expression was knocked down in whisker pad Merkel cells (Ikeda et al., 2014). In a model of sickle cell anemia, mice exhibiting dynamic allodynia showed increased SAI firing (Garrison et al., 2012). Another study showed that, in a similar model of Merkel cell deficiency $\left(K 5^{C r e}\right.$;Atoh $\left.1^{f l / f l}\right)$, no deficits were observed in baseline punctate mechanosensitivity (Neubarth et al., 2020). However, whether Merkel cells and/or A $\beta$ SAI LTMRs contribute to neuropathic pain has not been previously addressed.

In our experiments, male but not female Merkel cell KO mice exhibited a slight reduction in baseline paw withdrawal behavior to mechanical stimuli in two of four cohorts examined over several years, and this difference remained significant when analyzed across all cohorts. Following SNI surgery, we observed a reduction, but not elimination, of punctate mechanical hypersensitivity after nerve injury in male mice lacking Merkel cells in all four cohorts, a reduction corroborated by pooled analysis of all cohorts. This finding is consistent with a decrease in touchevoked allodynia. Moreover, our $\mathrm{K} 14^{\mathrm{Cre}} ; \mathrm{Atoh}^{+/+}$data argue that genetic background is not the basis of this phenotype. We also observed significantly reduced dynamic allodynia in hairy skin in two of four cohorts of male Merkel cell KOs and in glabrous skin in two of three cohorts of male KOs, and these decreases persisted in the pooled cohort analysis. The variable consequences of Merkel cell $\mathrm{KO}$ on baseline punctate mechanosensitivity and dynamic allodynia among cohorts might be attributable to a borderline phenotype, differences in technique between individual investigators and/or inherent behavioral differences between cohorts. Collectively, our results suggest that intact Merkel cell-A $\beta$ afferent signaling is rate-limiting for the full extent of punctate mechanical allodynia after sural-sparing nerve injury, and that there is a less conclusive possible contribution to basal mechanosensitivity and dynamic allodynia, with no apparent contribution to heat hyperalgesia. In the SNIt model, we observed no significant impact of Merkel cell deletion on mechanical sensitivity. However, the small extent of hypersensitivity in mice replete for Merkel cells in this model resulted in a restricted dynamic range in which to observe any such differences. It remains to be determined whether mechanical allodynia caused by other nerve injury models or inflammation is also influenced by Merkel cell KO.

One limitation of our study is that Merkel cells were absent throughout the lifetime of mice, altering the molecular phenotype of SAI neurons. We therefore cannot distinguish between a requirement for Merkel cells, per se, versus a requirement for normally developed SAI neurons. Furthermore, the density of Merkel cells in the glabrous skin sural territory, where our punctate stimuli were applied, is low, making Merkel cells in this territory questionable mediators of allodynia in the SNI model. One possible explanation for this paradox is that hairy skin Merkel cells and SAI neurons are being stimulated by filament application to closely juxtaposed glabrous skin, at least in the setting of hypersensitivity. Indeed, the inconsistent effects of Merkel cell KO on dynamic allodynia might be attributable to small but variable degrees of skin indentation in the hairy territory during dynamic skin brushing. We also cannot exclude the possibilities that abnormally developed SAI neurons in Merkel cell KOs exhibit an altered response to injury or that Merkel cells themselves might release signals that sensitize other cell types following nerve injury. It is also possible that Atoh $1 \mathrm{KO}$ in other cell types, such as keratinocytes, contribute to the observed phenotypes. Physiologic and molecular studies could distinguish among these possibilities. Additionally, our experiments would be complemented by the selective silencing of SAI neurons or examination of neuropathic pain in mice in which Merkel cell signaling is selectively compromised by Piezo2 KO.

One unexpected finding of our study was that the impact of Merkel cell KO on nerve injury-induced mechanical allodynia was confined to males. Sex differences in chronic pain, including neuropathic pain, are well documented in humans and animal studies (Smith et al., 2006; Torrance et al., 2006; Bouhassira et al., 2008; Hurley and Adams, 2008; Fillingim et al., 2009; Sorge et al., 2015; Taves et al., 2016; Mapplebeck et al., 2018). We did not control for reproductive cycle in our female mice and thus cannot draw conclusions on this variable. Electrophysiological studies performed on both sexes did not indicate whether there were differences in Merkel cell-A $\beta$ afferent signaling (Maksimovic et al., 2014) and a prior comparison revealed no difference in the total number of Merkel cells per paw between male and female mice (Maricich et al., 2012). In the present study, we observed a slightly lower Merkel cell density in the glabrous skin of naive male versus female mice that was not statistically replicated in a comparison of contralateral paws at day 28 after injury. However, even if this difference is real, its magnitude seems too small to explain our findings. Moreover, nerve injury-induced changes in Merkel cell density were similar between males and females. Ours is not the first study to report potential sex differences related to Merkel cell function. One previous study used a texture discrimination task in which female WT C57 mice preferred rough surfaces over smooth surfaces, whereas males showed no such preference (Maricich et al., 2012). In that study, Merkel cell KO eliminated the female preference for rough surfaces. Our findings suggest that male and female mice use input from SAI neurons differently in the setting of allodynia, and that this difference is unmasked under conditions of Merkel cell disruption. Additional studies will be required to determine whether these observations reflect sex differences in inputs from Merkel cell-A $\beta$ afferent complexes to specific populations of CNS neurons or in the impact of nerve injury on Merkel cell or SAI mechanosensory responsiveness. It should also be explored whether the Merkel cell-A $\beta$ afferent complexes play a disproportionate role in injury induced activation of spinal microglia or release of inflammatory mediators, phenomena that differ in male versus female mice (Loram et al., 2012; Sorge et al., 2015; Mapplebeck et al., 2016; Yu et al., 2020).

\section{References}

Bai L, Lehnert BP, Liu J, Neubarth NL, Dickendesher TL, Nwe PH, Cassidy C, Woodbury CJ, Ginty DD (2015) Genetic identification of an expansive mechanoreceptor sensitive to skin stroking. Cell 163:1783-1795.

Boada MD, Gutierrez S, Aschenbrenner CA, Houle TT, Hayashida K, Ririe DG, Eisenach JC (2015) Nerve injury induces a new profile of tactile and mechanical nociceptor input from undamaged peripheral afferents. J Neurophysiol 113:100-109.

Bouhassira D, Lanteri-Minet M, Attal N, Laurent B, Touboul C (2008) Prevalence of chronic pain with neuropathic characteristics in the general population. Pain 136:380-387.

Bourquin AF, Suveges M, Pertin M, Gilliard N, Sardy S, Davison AC, Spahn DR, Decosterd I (2006) Assessment and analysis of mechanical allodynialike behavior induced by spared nerve injury (SNI) in the mouse. Pain 122:14.e11-e14.

Campbell JN, Raja SN, Meyer RA, Mackinnon SE (1988) Myelinated afferents signal the hyperalgesia associated with nerve injury. Pain 32:89-94.

Carvell GE, Simons DJ (1990) Biometric analyses of vibrissal tactile discrimination in the rat. J Neurosci 10:2638-2648. 
Chang W, Kanda H, Ikeda R, Ling J, DeBerry JJ, Gu JG (2016) Merkel disc is a serotonergic synapse in the epidermis for transmitting tactile signals in mammals. Proc Natl Acad Sci USA 113:E5491-E5500.

Cheng L, Duan B, Huang T, Zhang Y, Chen Y, Britz O, Garcia-Campmany L, Ren X, Vong L, Lowell BB, Goulding M, Wang Y, Ma Q (2017) Identification of spinal circuits involved in touch-evoked dynamic mechanical pain. Nat Neurosci 20:804-814.

Dassule HR, Lewis P, Bei M, Maas R, McMahon AP (2000) Sonic hedgehog regulates growth and morphogenesis of the tooth. Development 127:4775-4785.

Decosterd I, Woolf CJ (2000) Spared nerve injury: an animal model of persistent peripheral neuropathic pain. Pain 87:149-158.

Dhandapani R, Arokiaraj CM, Taberner FJ, Pacifico P, Raja S, Nocchi L, Portulano C, Franciosa F, Maffei M, Hussain AF, de Castro Reis F, Reymond L, Perlas E, Garcovich S, Barth S, Johnsson K, Lechner SG, Heppenstall PA (2018) Control of mechanical pain hypersensitivity in mice through ligand-targeted photoablation of TrkB-positive sensory neurons. Nat Commun 9:1640.

Doucet YS, Woo SH, Ruiz ME, Owens DM (2013) The touch dome defines an epidermal niche specialized for mechanosensory signaling. Cell Rep 3:1759-1765.

English KB, Kavka-Van Norman D, Horch K (1983) Effects of chronic denervation in type I cutaneous mechanoreceptors (Haarscheiben). Anat Rec 207:79-88.

Fagan BM, Cahusac PM (2001) Evidence for glutamate receptor mediated transmission at mechanoreceptors in the skin. Neuroreport 12:341-347.

Feng J, Luo J, Yang P, Du J, Kim BS, Hu H (2018) Piezo2 channel-Merkel cell signaling modulates the conversion of touch to itch. Science 360:530533.

Fillingim RB, King CD, Ribeiro-Dasilva MC, Rahim-Williams B, Riley JL 3rd (2009) Sex, gender, and pain: a review of recent clinical and experimental findings. J Pain 10:447-485.

Garrison SR, Kramer AA, Gerges NZ, Hillery CA, Stucky CL (2012) Sickle cell mice exhibit mechanical allodynia and enhanced responsiveness in light touch cutaneous mechanoreceptors. Mol Pain 8:62.

Halata Z, Grim M, Bauman KI (2003) Friedrich Sigmund Merkel and his 'Merkel cell,' morphology, development, and physiology: review and new results. Anat Rec A Discov Mol Cell Evol Biol 271:225-239.

Hartschuh W, Weihe E (1980) Fine structural analysis of the synaptic junction of Merkel cell-axon-complexes. J Invest Dermatol 75:159-165.

Hitchcock IS, Genever PG, Cahusac PM (2004) Essential components for a glutamatergic synapse between Merkel cell and nerve terminal in rats. Neurosci Lett 362:196-199.

Hoffman BU, Baba Y, Griffith TN, Mosharov EV, Woo SH, Roybal DD, Karsenty G, Patapoutian A, Sulzer D, Lumpkin EA (2018) Merkel cells activate sensory neural pathways through adrenergic synapses. Neuron 100:1401-1413.e1406.

Hurley RW, Adams MC (2008) Sex, gender, and pain: an overview of a complex field. Anesth Analg 107:309-317.

Iggo A, Muir AR (1969) The structure and function of a slowly adapting touch corpuscle in hairy skin. J Physiol 200:763-796.

Ikeda R, Cha M, Ling J, Jia Z, Coyle D, Gu JG (2014) Merkel cells transduce and encode tactile stimuli to drive Abeta-afferent impulses. Cell 157:664675.

Ko MH, Yang ML, Youn SC, Lan CT, Tseng TJ (2016) Intact subepidermal nerve fibers mediate mechanical hypersensitivity via the activation of protein kinase $\mathrm{C}$ gamma in spared nerve injury. Mol Pain 12:174480691665618.

Koltzenburg M, Torebjork HE, Wahren LK (1994) Nociceptor modulated central sensitization causes mechanical hyperalgesia in acute chemogenic and chronic neuropathic pain. Brain 117:579-591.

Li L, Rutlin M, Abraira VE, Cassidy C, Kus L, Gong S, Jankowski MP, Luo W, Heintz N, Koerber HR, Woodbury CJ, Ginty DD (2011) The functional organization of cutaneous low-threshold mechanosensory neurons. Cell 147:1615-1627.

Loram LC, Sholar PW, Taylor FR, Wiesler JL, Babb JA, Strand KA, Berkelhammer D, Day HE, Maier SF, Watkins LR (2012) Sex and estradiol influence glial pro-inflammatory responses to lipopolysaccharide in rats. Psychoneuroendocrinology 37:1688-1699.

Maksimovic S, Nakatani M, Baba Y, Nelson AM, Marshall KL, Wellnitz SA, Firozi P, Woo SH, Ranade S, Patapoutian A, Lumpkin EA (2014)
Epidermal Merkel cells are mechanosensory cells that tune mammalian touch receptors. Nature 509:617-621.

Mapplebeck JC, Beggs S, Salter MW (2016) Sex differences in pain: a tale of two immune cells. Pain 157 Suppl 1:S2-S6.

Mapplebeck JC, Dalgarno R, Tu Y, Moriarty O, Beggs S, Kwok CH, Halievski K, Assi S, Mogil JS, Trang T, Salter MW (2018) Microglial P2X4R-evoked pain hypersensitivity is sexually dimorphic in rats. Pain 159:1752-1763.

Maricich SM, Wellnitz SA, Nelson AM, Lesniak DR, Gerling GJ, Lumpkin EA, Zoghbi HY (2009) Merkel cells are essential for light-touch responses. Science 324:1580-1582.

Maricich SM, Morrison KM, Mathes EL, Brewer BM (2012) Rodents rely on Merkel cells for texture discrimination tasks. J Neurosci 32:3296-3300.

McGowan KM, Coulombe PA (1998) Onset of keratin 17 expression coincides with the definition of major epithelial lineages during skin development. J Cell Biol 143:469-486.

Mills LR, Nurse CA, Diamond J (1989) The neural dependency of Merkel cell development in the rat: the touch domes and foot pads contrasted. Dev Biol 136:61-74

Moll I, Paus R, Moll R (1996) Merkel cells in mouse skin: intermediate filament pattern, localization, and hair cycle-dependent density. J Invest Dermatol 106:281-286.

Neubarth NL, Emanuel AJ, Liu Y, Springel MW, Handler A, Zhang Q, Lehnert BP, Guo C, Orefice LL, Abdelaziz A, DeLisle MM, Iskols M, Rhyins J, Kim SJ, Cattel SJ, Regehr W, Harvey CD, Drugowitsch J, Ginty DD (2020) Meissner corpuscles and their spatially intermingled afferents underlie gentle touch perception. Science 368:eabb2751.

Nurse CA, Diamond J (1984) A fluorescent microscopic study of the development of rat touch domes and their Merkel cells. Neuroscience 11:509520.

Nurse CA, Macintyre L, Diamond J (1984a) A quantitative study of the time course of the reduction in Merkel cell number within denervated rat touch domes. Neuroscience 11:521-533.

Nurse CA, Macintyre L, Diamond J (1984b) Reinnervation of the rat touch dome restores the Merkel cell population reduced after denervation. Neuroscience 13:563-571.

Ochs G, Schenk M, Struppler A (1989) Painful dysaesthesias following peripheral nerve injury: a clinical and electrophysiological study. Brain Res 496:228-240.

Pan B, Byrnes K, Schwartz M, Hansen CD, Campbell CM, Krupiczojc M, Caterina MJ, Polydefkis M (2016) Peripheral neuropathic changes in pachyonychia congenita. Pain 157:2843-2853.

Ranade SS, Woo SH, Dubin AE, Moshourab RA, Wetzel C, Petrus M, Mathur J, Begay V, Coste B, Mainquist J, Wilson AJ, Francisco AG, Reddy K, Qiu Z, Wood JN, Lewin GR, Patapoutian A (2014) Piezo2 is the major transducer of mechanical forces for touch sensation in mice. Nature 516:121-125.

Reed-Geaghan EG, Wright MC, See LA, Adelman PC, Lee KH, Koerber HR, Maricich SM (2016) Merkel cell-driven BDNF signaling specifies SAI neuron molecular and electrophysiological phenotypes. J Neurosci 36:4362-4376

Shields SD, Eckert WA 3rd, Basbaum AI (2003) Spared nerve injury model of neuropathic pain in the mouse: a behavioral and anatomic analysis. J Pain 4:465-470.

Smith YR, Stohler CS, Nichols TE, Bueller JA, Koeppe RA, Zubieta JK (2006) Pronociceptive and antinociceptive effects of estradiol through endogenous opioid neurotransmission in women. J Neurosci 26:5777-5785.

Sorge RE, Mapplebeck JC, Rosen S, Beggs S, Taves S, Alexander JK, Martin LJ, Austin JS, Sotocinal SG, Chen D, Yang M, Shi XQ, Huang H, Pillon NJ, Bilan PJ, Tu Y, Klip A, Ji RR, Zhang J, Salter MW, et al. (2015) Different immune cells mediate mechanical pain hypersensitivity in male and female mice. Nat Neurosci 18:1081-1083.

Taves S, Berta T, Liu DL, Gan S, Chen G, Kim YH, Van de Ven T, Laufer S, Ji RR (2016) Spinal inhibition of p38 MAP kinase reduces inflammatory and neuropathic pain in male but not female mice: sex-dependent microglial signaling in the spinal cord. Brain Behav Immun 55:70-81.

Torrance N, Smith BH, Bennett MI, Lee AJ (2006) The epidemiology of chronic pain of predominantly neuropathic origin: results from a general population survey. J Pain 7:281-289.

Walcher J, Ojeda-Alonso J, Haseleu J, Oosthuizen MK, Rowe AH, Bennett NC, Lewin GR (2018) Specialized mechanoreceptor systems in rodent glabrous skin. J Physiol 596:4995-5016. 
Woo SH, Ranade S, Weyer AD, Dubin AE, Baba Y, Qiu Z, Petrus M, Miyamoto T, Reddy K, Lumpkin EA, Stucky CL, Patapoutian A (2014) Piezo2 is required for Merkel-cell mechanotransduction. Nature 509:622-626.

Woo SH, Lumpkin EA, Patapoutian A (2015) Merkel cells and neurons keep in touch. Trends Cell Biol 25:74-81.

Woodbury CJ, Koerber HR (2007) Central and peripheral anatomy of slowly adapting type I low-threshold mechanoreceptors innervating trunk skin of neonatal mice. J Comp Neurol 505:547-561.

Wright MC, Logan GJ, Bolock AM, Kubicki AC, Hemphill JA, Sanders TA, Maricich SM (2017) Merkel cells are long-lived cells whose production is stimulated by skin injury. Dev Biol 422:4-13.
Xiao Y, Thoresen DT, Williams JS, Wang C, Perna J, Petrova R, Brownell I (2015) Neural Hedgehog signaling maintains stem cell renewal in the sensory touch dome epithelium. Proc Natl Acad Sci USA 112:7195-7200.

Xu ZZ, Kim YH, Bang S, Zhang Y, Berta T, Wang F, Oh SB, Ji RR (2015) Inhibition of mechanical allodynia in neuropathic pain by TLR5-mediated A-fiber blockade. Nat Med 21:1326-1331.

Yu X, Liu H, Hamel KA, Morvan MG, Yu S, Leff J, Guan Z, Braz JM, Basbaum AI (2020) Dorsal root ganglion macrophages contribute to both the initiation and persistence of neuropathic pain. Nat Commun 11:264

Zhu YF, Henry JL (2012) Excitability of Abeta sensory neurons is altered in an animal model of peripheral neuropathy. BMC Neurosci 13:15. 